\title{
Evaluation of Equilibrium Sorption Isotherm Equations
}

\author{
Chiachung Chen*
}

Department of Bio-Industrial Mechantronics Engineering, National ChungHsing University, Taichung, 40227, Taiwan

\begin{abstract}
The sorption isotherm is important information for evaluating the ability of an adsorption system to treat the industrial waste water. In this study, eleven datasets from literatures were selected and three two-parameter and threeparameter equations were used to evaluate adsorption systems. Quantitative criteria included six error functions, and the quantitative criterion was residual plots. Isotherm constants differed by linearization and nonlinear regression analysis, especially for the three-parameter equations. The results indicated the inconsistent results of the error functions for selecting the adequate equations. Residual plots were useful to observe the fitting ability of isotherm equations. Temperature has a significant effect on isotherm constants.
\end{abstract}

Keywords: Isotherm equation, Error functions, Residual plots.

\section{INTRODUCTION}

Environmental protection has become the basic requirement of industry development. Water or industrial wastewater treatment is an emergency technique for saving the natural environment. Adsorption is a useful technique for purification and separation in treating industrial waste water. With adsorption, pollutants or toxic materials can be removed from aqueous or non-aqueous solutions.

Biological materials have been applied widely used for the adsorption of heavy metals, because of their inexpensive and the ability to bind pollutants. With a constant adsorbate concentration, the absorbent concentration can reach equilibrium at a fixed temperature. The distribution of the concentrations of adsorbate and adsorbent is called the sorption isotherm. The sorption isotherm must be established to evaluate the capacity of an adsorption system. Parameters of sorption isotherm can be used to describe the surface properties of adsorbents and other properties. Factors other than temperature that affected sorption properties included particle size, metal ion [1,2] and $\mathrm{pH}[3-5]$.

Four isotherms were selected to compare predictive accuracy with single isotherm data for sorption of three heavy metal ions by pipe bark and to determine binary sorption isotherms [1]. The Langmuir isotherm model was less accurate. cy than other models. Seven sorption models were used to evaluate the sorption of three metal ions from aqueous solution by peat [2]. Six error functions were proposed to evaluate the fitting ability of these models. The Sips equation was the best model for the experimental data for $\mathrm{Cu}, \mathrm{Ni}$ and $\mathrm{Pb}$. Three isotherms models were used to test tree fern as a sorbent system for removing three types of metal ions [6]. The Langmuir and Redlich-Peterson isotherms could

*Address correspondence to this author at the Department of Bio-Industrial Mechantronics Engineering, National ChungHsing University, Taichung, 40227, Taiwan; Tel: +886422857562; Fax: +886422857135;

E-mail: ccchen@dragon.nchu.edu.tw represent the experimental data well. The Langmuir model was extended to predict multi-component sorption data and the fitting ability of the new model was tested [7]. Seven models were tested with the coefficient of determination and the value of the sum of normalized errors for biosorption of ochratoxin A (OA) on yeast biomass as the decontamination agent [8]. The Hill, Freundlich and BET equations were appropriate models.

Many sorption isotherm models have been proposed to assess their ability to fit experimental data. Six twoparameter and nine three-parameter models have been described [9]. Some models were modified to describe multicomponent adsorption. More parameters were incorporated into the original form of the model and termed extension isotherm models $[1,7,10]$.

For fitting a nonlinear isotherm model as a linear model, the dependent and independent variables are transformed [2,6,8,11-14]. The transformed dependent variables are then calculated and evaluated by different error equations. The problems in variable transformation and the regression results have been discussed [9,15-17].

The criteria to evaluate the error distribution between the experimental data and the predictive values of isotherm models are called error functions. Nine error functions have been reviewed [9]. Some researchers select one or two criteria, such as the coefficient of determination $\mathrm{R}^{2}$ and $\chi^{2}$ [7,11-14,18]. Others adopted several criteria to determine with best performance for all functions [2,8,11].

Common errors in analyzing of sorption isotherm data have been discussed [16]. With linearization, the assumption of experimental error is violated. The variance errors lie in the dependent and independent variables for linear and nonlinear isotherm models. Other errors are abuse of $\mathrm{R}^{2}$ and neglecting to account for the different degrees of freedom for model comparison [17]. 
The error functions are only the quantitative criteria for model evaluation. The qualitative criterion is residual plots [19-20]. However, this criterion has previously been used to evaluate only the assumption of homoskedasity [21].

This study used eleven datasets from the literature to evaluate the appropriate model describing sorption isotherm data. Six isotherm models, including two-parameter and three-parameter equations, were used to evaluate the fitting ability of the models. The quantitative criteria included six error functions and the qualitative criterion was residual plots. The effect of temperature on constants was also exampled.

\section{METHODS}

\subsection{Literature Survey}

The eleven datasets, including different temperatures, metal ions and adsorbate range are listed in Table $\mathbf{1}$.

\subsection{Isotherm Equations}

Six isotherms were adopted.

\subsubsection{Two-parameter Models}

\subsubsection{Freundlich Isotherm}

$\mathrm{q}_{\mathrm{e}}=\mathrm{K}_{\mathrm{F}} \mathrm{C}_{\mathrm{e}}^{\text {br }}$

where $\mathrm{q}_{\mathrm{e}}$ is the amount of solute adsorbed at equilibrium, $\mathrm{C}_{\mathrm{e}}$ is the equilibrium concentration, and $\mathrm{K}_{\mathrm{F}}$ and br are the Freundlich constants. tion,

Equation (1) can be expressed as an exponential equa-

$\mathrm{Y}=\mathrm{ax}$

where $\mathrm{a}$ and $\mathrm{b}$ are constants.

\subsubsection{Langmuir Isotherm}

$q_{e}=\frac{k_{L} C_{e}}{1+a_{L} C_{e}}$ where $\mathrm{k}_{\mathrm{L}}$ and $\mathrm{a}_{\mathrm{L}}$ are the Langmuir isotherm constants.

Equation (3) can be written as follows:

$y=\frac{a x}{1+b x}$

\subsubsection{Tempkim isotherm}

$q_{e}=\frac{R T}{b_{T}} \operatorname{In}\left(\mathrm{A}_{\mathrm{T}} C_{e}\right)$

$=\mathrm{B}_{\mathrm{T}} \operatorname{In}\left(A_{\mathrm{T}} C_{e}\right)$

where $\mathrm{R}$ is the gas constant, $\mathrm{T}$ is the temperature in $\mathrm{K}$, and $\mathrm{A}_{\mathrm{T}}$ and $\mathrm{B}_{\mathrm{T}}$ are the Tempkim isotherm constants.

Equation (5) can be transformed as follows

$\mathrm{Y}=\mathrm{B}_{\mathrm{T}}\left(\operatorname{In} \mathrm{A}_{\mathrm{T}}+\operatorname{In} \mathrm{C}_{\mathrm{e}}\right)$

$=\mathrm{a}+\mathrm{b} \operatorname{In} \mathrm{x}$

\subsubsection{Three-parameter Models}

\subsubsection{Redlich-Paterson Isotherm}

$q_{e}=\frac{K_{R} C_{e}}{1+a_{R} C_{e}^{B}}$

where $K_{R}, a_{R}$ and $B$ are the Redlich-Peterson isotherm constants.

Equation (7) can be written as following:

$y=\frac{a x}{c+x^{b}}$

where $\mathrm{a}=\mathrm{K}_{\mathrm{R}} / \mathrm{a}_{\mathrm{R}}, \mathrm{b}=\mathrm{B}$ and $\mathrm{c}=1 / \mathrm{a}_{\mathrm{R}}$.

\subsubsection{Hill Isotherm}

$q_{e}=\frac{q_{S H} C_{e}^{n H}}{K_{D}+C_{e}^{n H}}$

where $\mathrm{q}_{\mathrm{SH}}, \mathrm{nH}$ and $\mathrm{K}_{\mathrm{D}}$ are the Hill isotherm constants.

Equation (9) can be expressed as follows:

Table 1. Literature Sources Giving Sorption Isotherm Data

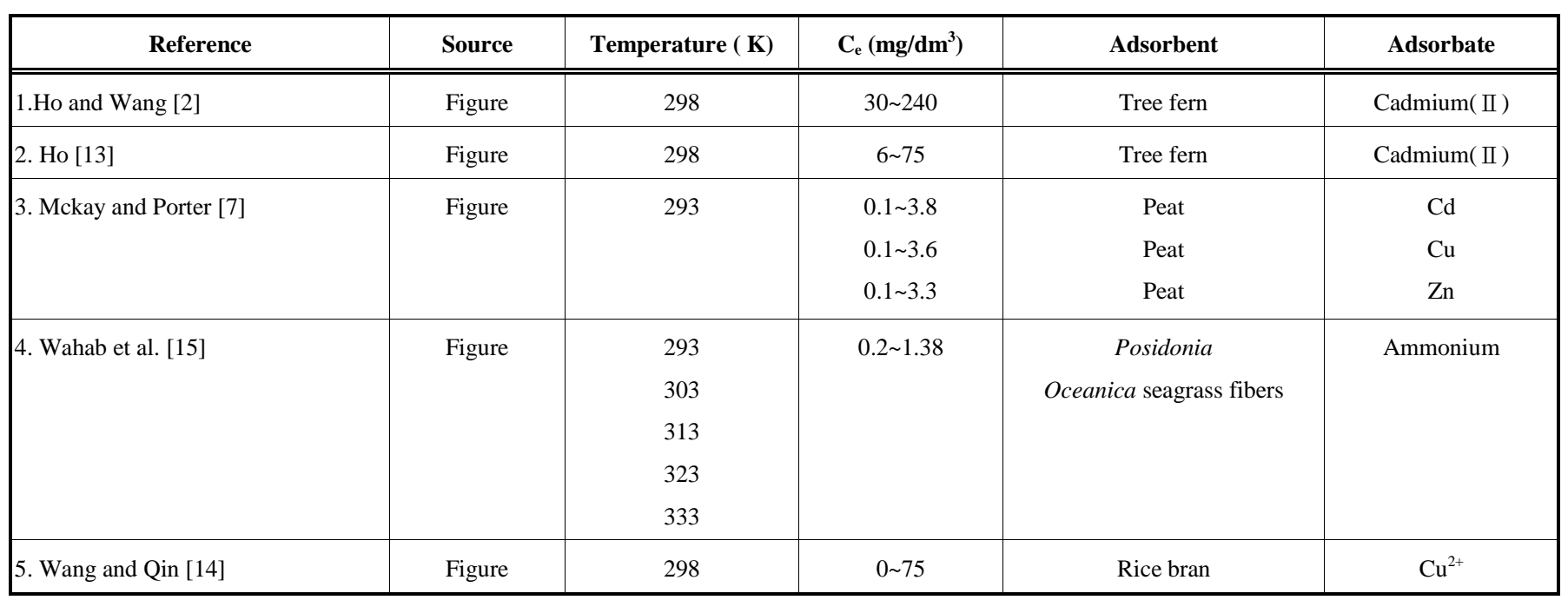




$$
y=\frac{a x^{b}}{c+x^{b}}
$$

\subsubsection{Toth Isotherm}

$q_{e}=\frac{K_{T} C_{e}}{\left(\alpha_{T}+C_{e}\right)^{1 / t}}$

where $K_{T}, \alpha_{T}$ and $t$ are the Toth isotherm constants

Equation (11) is expressed as follows:

$y=\frac{a x}{(c+x)^{b}}$

Two models, Sips and Koble-Corrigan isotherms, had the same form as previous equation.

For the Sips model,

$q_{e}=\frac{K_{s} C_{e}^{B s}}{1+\alpha_{s} C_{e}^{B s}}$

where $K_{s}, B_{s}$ and $\alpha_{s}$ are the Sips isotherm constants.

Equation (13) has the same form as Equation (10), where $\mathrm{a}=\mathrm{K}_{\mathrm{s}} / \alpha_{\mathrm{s}}, \mathrm{b}=\mathrm{B}_{\mathrm{s}}$ and $\mathrm{c}=1 / \alpha_{\mathrm{s}}$.

For the Koble-Corrigan model,

$q_{e}=\frac{A_{k} C e^{n}}{1+B_{k} C_{e}^{n}}$

where $A_{k}, B_{k}$ and $n$ are the Koble-Corrigan isotherm constants.

Equation (14) has the same form as Equation (10), where $\mathrm{a}=\mathrm{A}_{\mathrm{k}} / \mathrm{B}_{\mathrm{k}}, \mathrm{b}=\mathrm{n}$ and $\mathrm{c}=1 / \mathrm{A}_{\mathrm{k}}$.

The Sips and Koble-Corrigan models were not be used to evaluate fitting ability.

\subsection{Error Functions}

\subsubsection{Quantitative Criteria}

Six quantitative criteria from the literatures were examined $[2,7-9,11-14]$.

\subsubsection{Coefficient of Determination, $R^{2}$}

\subsubsection{Standard Error of Estimate, $s$}

$$
s=\left(\left(y_{i}-\hat{y_{i}}\right)^{2} / n-p\right)^{0.5}
$$

where $y_{i}$ is the predicted value of the isotherm model, $\mathrm{y}_{\mathrm{i}}$ is the experimental data, $\mathrm{n}$ is the number of data and $\mathrm{p}$ is the number of parameters.

\subsubsection{Average Relative Error, ARE}

$$
A R E=\frac{100}{n} \sum\left|\frac{y_{i}-\hat{y_{i}}}{y_{i}}\right|
$$

\subsubsection{Hybrid Fractional Error Function, HYBRID}

$$
\text { HYBRID }=\frac{100}{n-p} \sum\left|\frac{y_{i}-\hat{y_{i}}}{y_{i}}\right|
$$

\subsubsection{Sum of Absolute Error, EABS}

$$
E A B S=\sum\left|y_{i}-\hat{y_{i}}\right|
$$

\subsubsection{Marquardt's Percent Standard Deviation, MPSD}

$M P S D=100\left(\frac{1}{n-p} \sum\left(\frac{y_{i}-\hat{y}_{i}}{y_{i}}\right)^{2}\right)^{0.5}$

\subsubsection{Qualitative Criterion}

The residual plot is an important criterion to assess the adequateness of a regression model (Draper and Smith, 1981; Myers, 1986). The distribution between the model predictive errors (residuals) versus predictive values is called the residual plots. A residual plot with a clean pattern indicated that the isotherm model has fixed model errors and is not adequate. A residual plot with a uniform distribution represented an adequate model [19-20].

\subsection{The Linearization Problems}

For some nonlinear isotherm models, data are transformed to linearization for regression analysis easily. However, this process changes the error structure of the data was changed. The Freundlich isotherm model is used to illustrate the violation of the error structure with transformation.

According to the assumption of regression analysis, the error in the dependent variable is additive error.

$\mathrm{q}_{\mathrm{ei}}=\mathrm{K}_{\mathrm{F}} \mathrm{C}_{\mathrm{e}}^{\mathrm{br}}+\mathrm{e}_{\mathrm{i}}$

where $e_{i}$ is the additive error of the model.

The regression model for transformed data is as follows:

$\operatorname{In}\left(\mathrm{q}_{\mathrm{ei}}\right)=\operatorname{In} \mathrm{K}_{\mathrm{F}}+\mathrm{br} \operatorname{In}\left(\mathrm{C}_{\mathrm{e})}+\mathrm{e}_{\mathrm{i}}^{*}\right.$

The In $\left(\mathrm{q}_{\mathrm{ei}}\right)$ transformed back to the original form results in the following,

$\mathrm{q}_{\mathrm{ei}}=\mathrm{K}_{\mathrm{F}} \mathrm{C}_{\mathrm{e}}^{\mathrm{br}} \operatorname{Exp}\left(\mathrm{e}_{\mathrm{i}}^{*}\right)$

The error structures of Equations. (20) and (22) are different, that is, data transformation affected the error structure and could also violate the assumption of homogeneous variance.

Considering the problems with linearization, the six isotherm equations used in this study were also studied by nonlinear regression analysis technique.

\subsection{Statistical Analysis}

Constants were estimated by nonlinear regression analysis with statistical software Sigma plot v10.0 (SPSS Inc., Chicago. IL).

\section{RESULTS AND DISCUSSIONS}

\subsection{Comparison of Constants with Linearization and Nonlinear Regression}

The isotherm constants with linearization and nonlinear regression analysis of datasets are listed in Table 2 . Two 
Table 2. Comparison of Constants of Linearization and Nonlinear Isotherm Equations

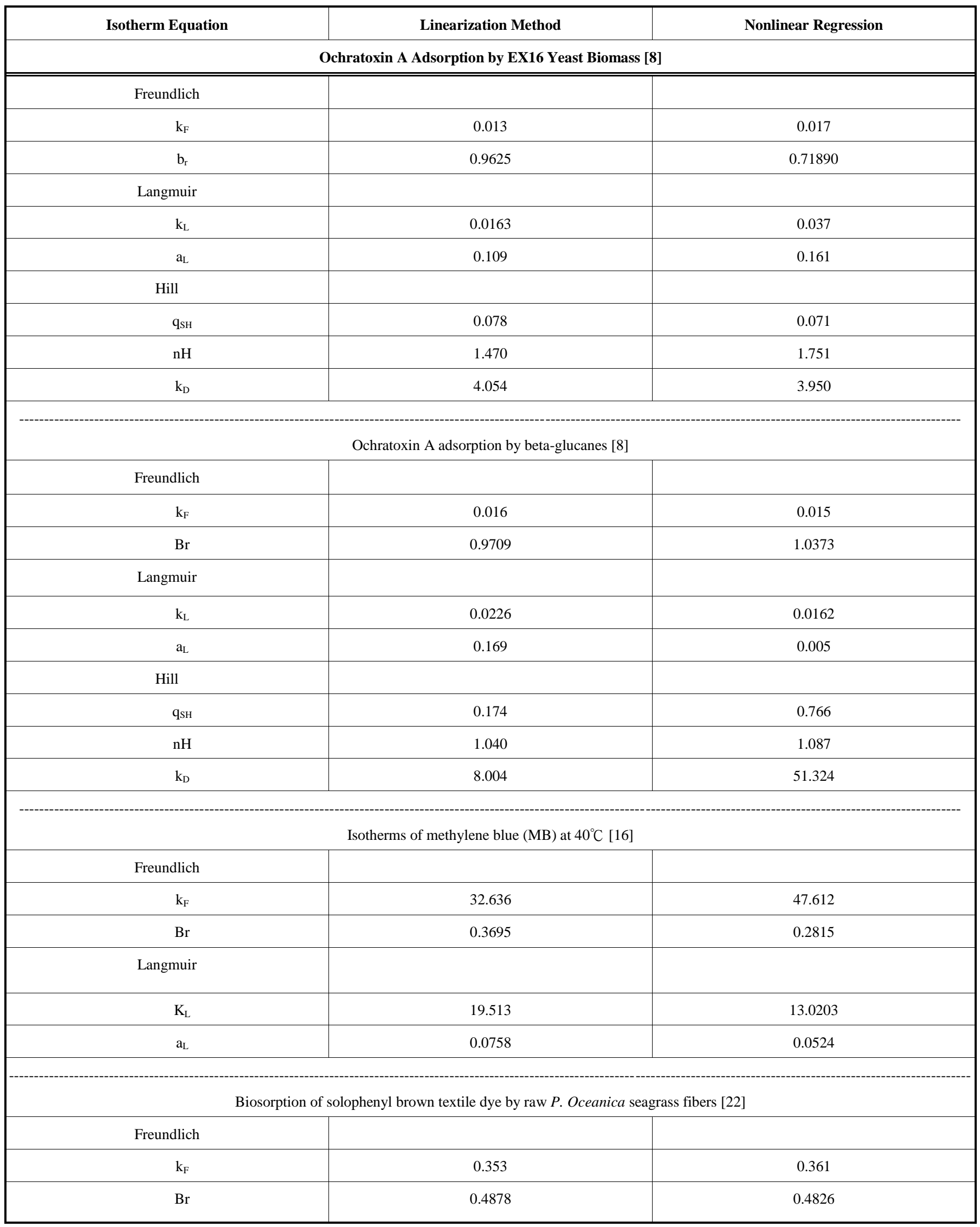


Table 2 Contd.....

\begin{tabular}{|c|c|c|}
\hline Langmuir & & 0.132 \\
\hline $\mathrm{k}_{\mathrm{L}}$ & 0.140 & 0.033 \\
\hline $\mathrm{a}_{\mathrm{L}}$ & 0.036 & 1.189 \\
\hline Redlich-Peterson & & 2.806 \\
\hline $\mathrm{k}_{\mathrm{R}}$ & 0.552 & 0.548 \\
\hline $\mathrm{a}_{\mathrm{R}}$ & 1.023 & 0.598 \\
\hline $\mathrm{B}$ & 0.50 \\
\hline
\end{tabular}

regression methods produced different constants. For the ochratoxin A (OA) adsorption onto EX16 yeast biomass [8], the br value of the Freundlich equation was 0.9625 for the linearization equation and 0.7189 for the nonlinear equations. The $\mathrm{k}_{\mathrm{L}}$ and $\mathrm{a}_{\mathrm{L}}$ values of the Langmuir equation were 0.0163 and 0.109 with linearization, and 0.037 and 0.161 for nonlinear equation.

The difference between constants with linearization and nonlinear analysis is presented for the Langmuir and Hill equations with $\mathrm{OA}$ adsorption data onto beta-glucanes. The constants of the Hill equation, $\mathrm{q}_{\mathrm{SH}}, \mathrm{nH}$ and $\mathrm{k}_{\mathrm{D}}$, were 0.174 , 1.040 and 8.004 with linearization and 0.766, 1.087 and 51.322 for nonlinear analysis.

For the constants $\mathrm{k}_{\mathrm{f}}$ and br for the Freundlich equation with sorption data of $\mathrm{MB}$ at $40^{\circ} \mathrm{C}$ [21] and for the constants of Redlich-Peterson equation $\mathrm{k}_{\mathrm{R}}, \mathrm{a}_{\mathrm{R}}$ and $\mathrm{B}$ with biosorption of solophenyl Brown textile dye onto raw P. Oceanica seagrass fibers [22], isotherm constants of three-parameter equations significantly different by regression method.

\subsection{Three Literatures Datasets}

The estimated isotherm constants and error functions for the six isotherm equations for three datasets are listed in Table 3. For the Ho and Wang data [2], the Toth equation produced the highest $\mathrm{R}^{2}$ value and the Hill equation had the lowest EABS value. However, the Langmuir equation produced smallest s, ARE, HYBRID and MPSD values. The results for error functions were inconsistent.

The relationship between adsorbate and adsorbent concentrations and the predictive curves of the six equations is presented in Fig. (1). Visually determining the fitting ability

$\begin{array}{ll}\bullet \text { measured values } \longrightarrow \text { Freundlich } \quad \longrightarrow \text { Langmuir } \quad \longrightarrow \text { Tempkim } \\ \longrightarrow \text { Redlich-Peterson } \longrightarrow \text { Hill } & \longrightarrow \text { Toth }\end{array}$

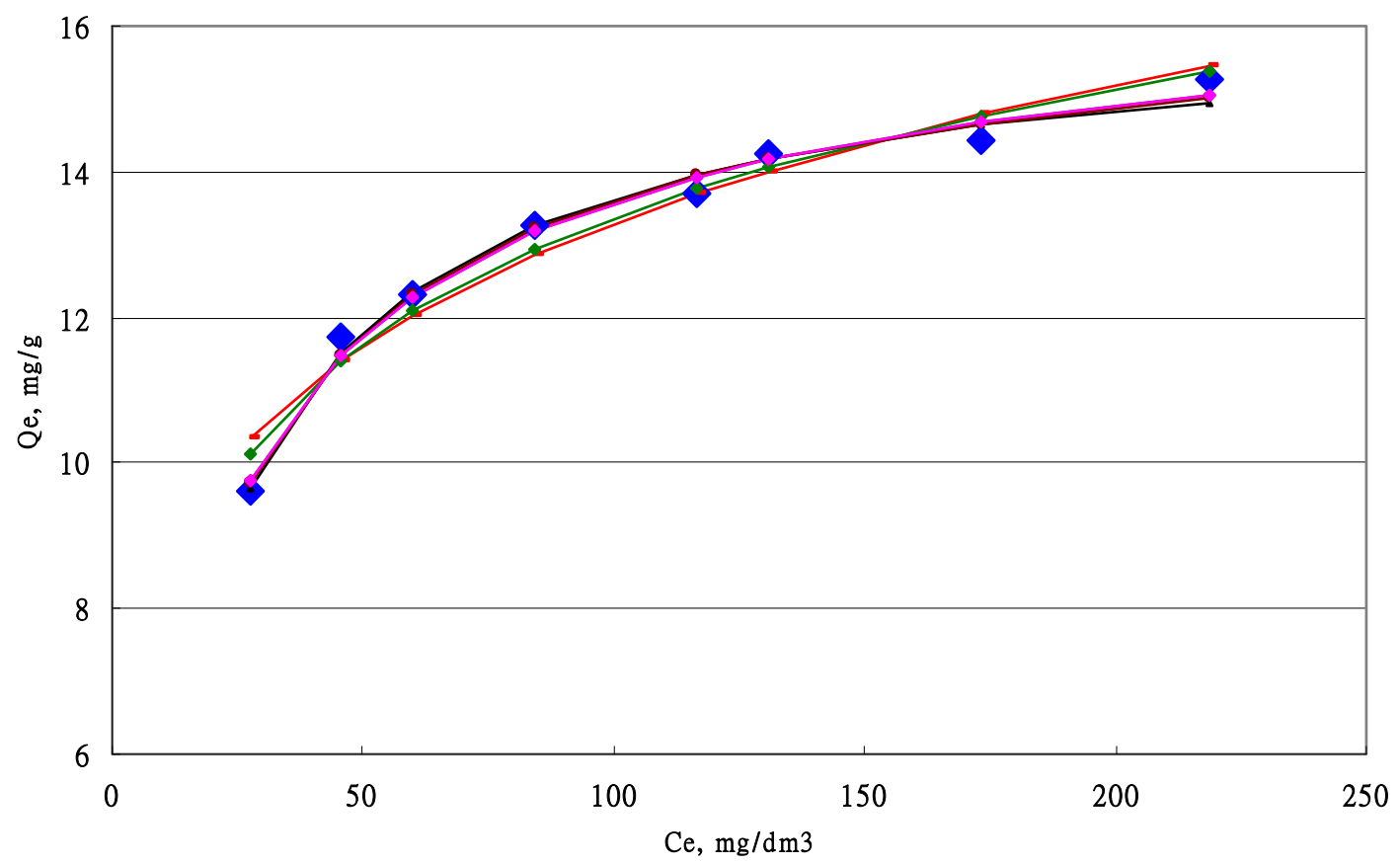

Fig. (1). Sorption isotherms for Ca by tree fern for six isotherm equations. 
is difficult. Residual plots provide a useful tool (Fig. 2). Residual plots showed clean patterns for the Freundlich and
Tempkim equations and uniform distributions for the Langmuir, Redlich-Peterson, Hill and Toth equations.

Table 3. Isotherm Constants and Error Functions for Six Isotherm Equations (Data from Three Publications)

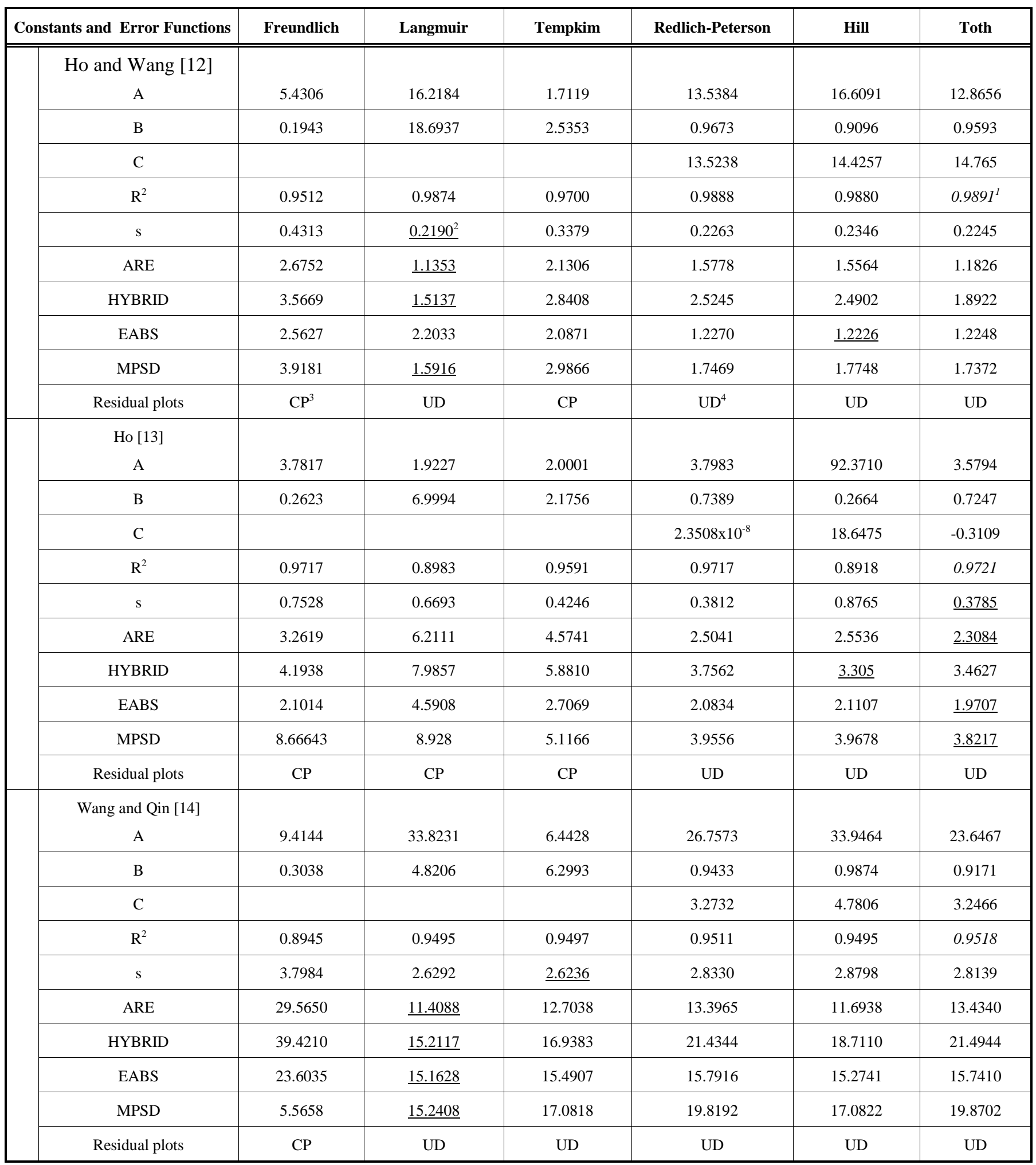

1. Letters in italics represent maximum value.

2. Letters in bold represent minimum value

3. CP: clean pattern of residual plots

4. UD: uniform distribution of residual plots 


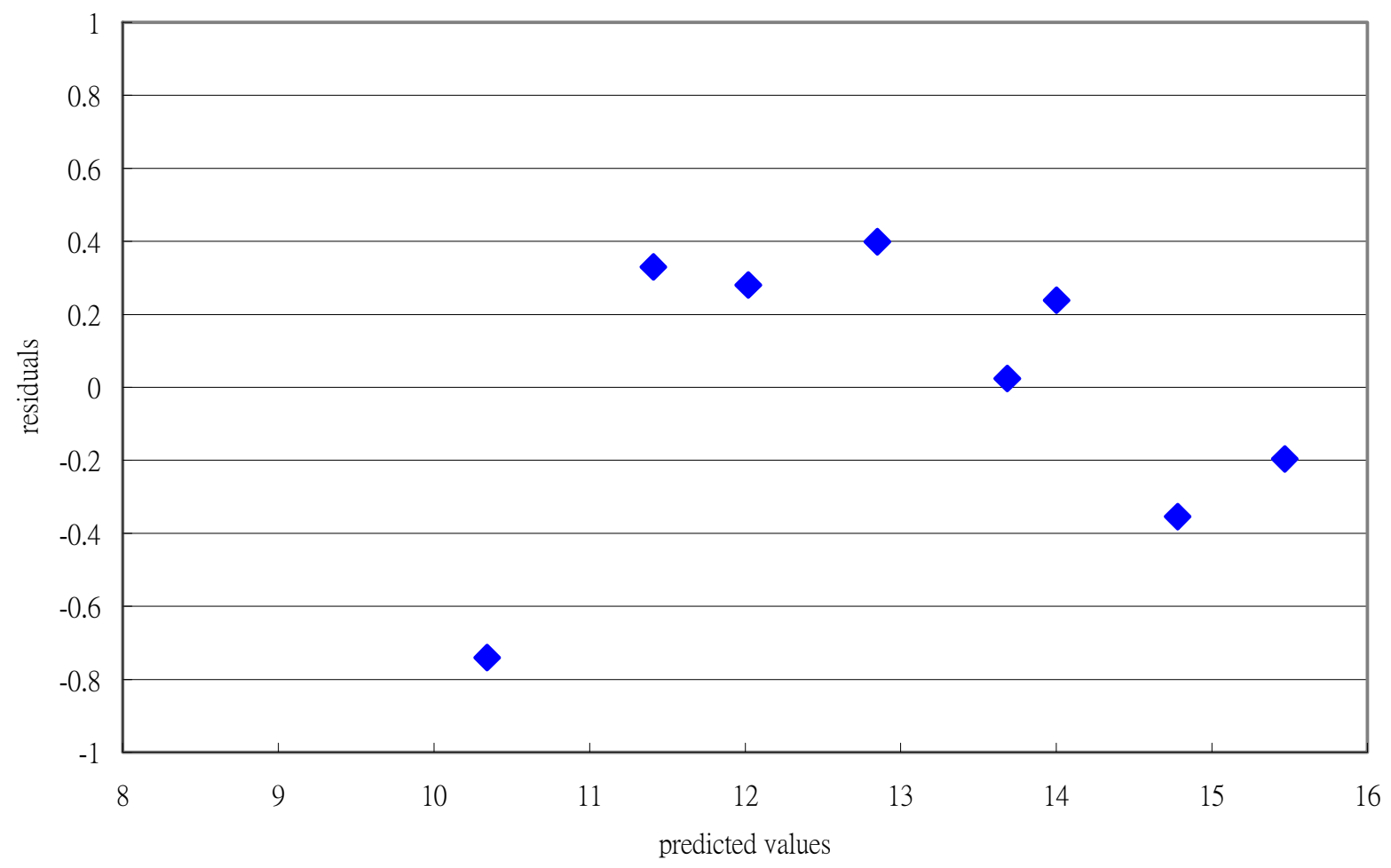

(2a) Freundlich equation

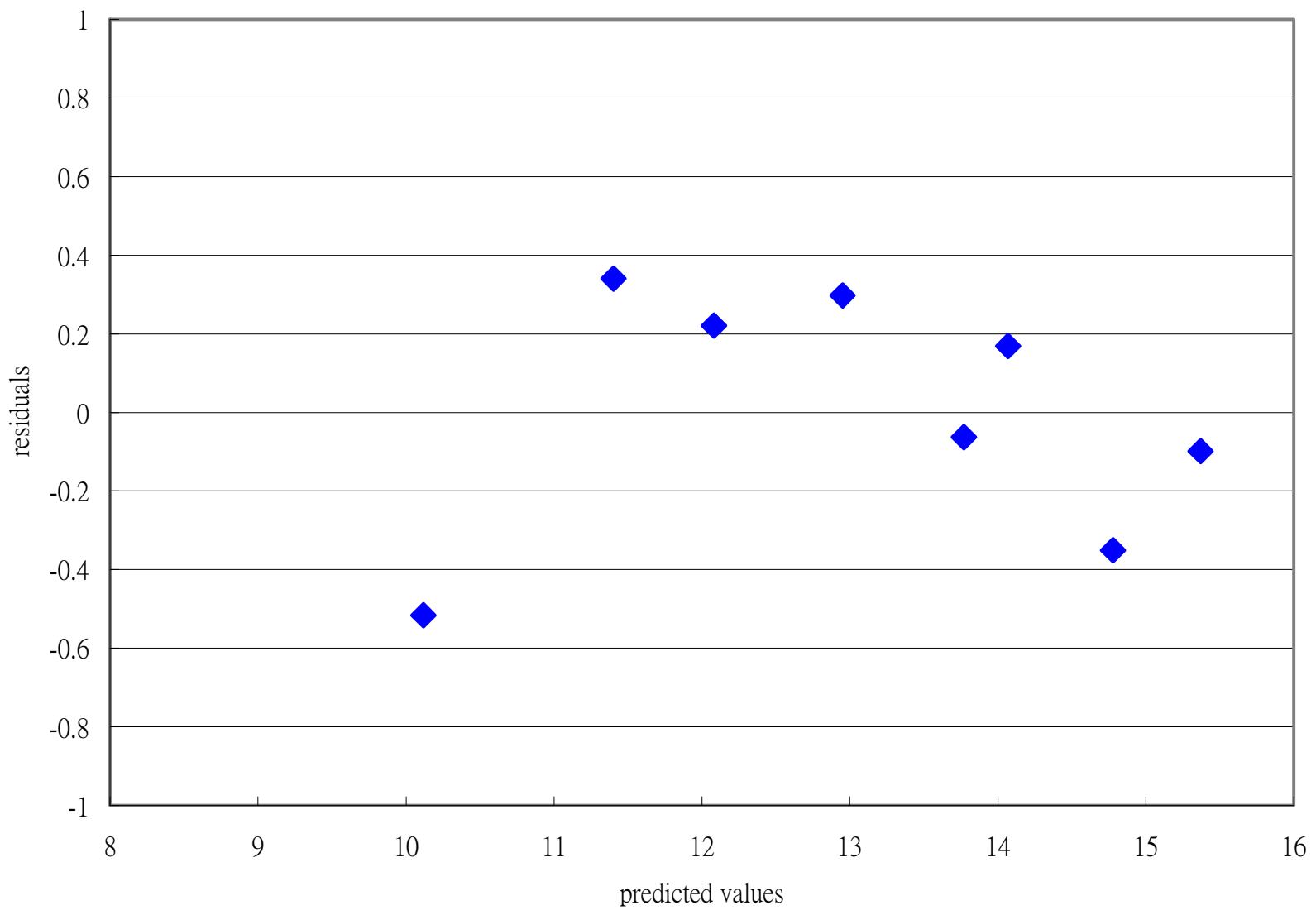

(2b) Langmuir equation 


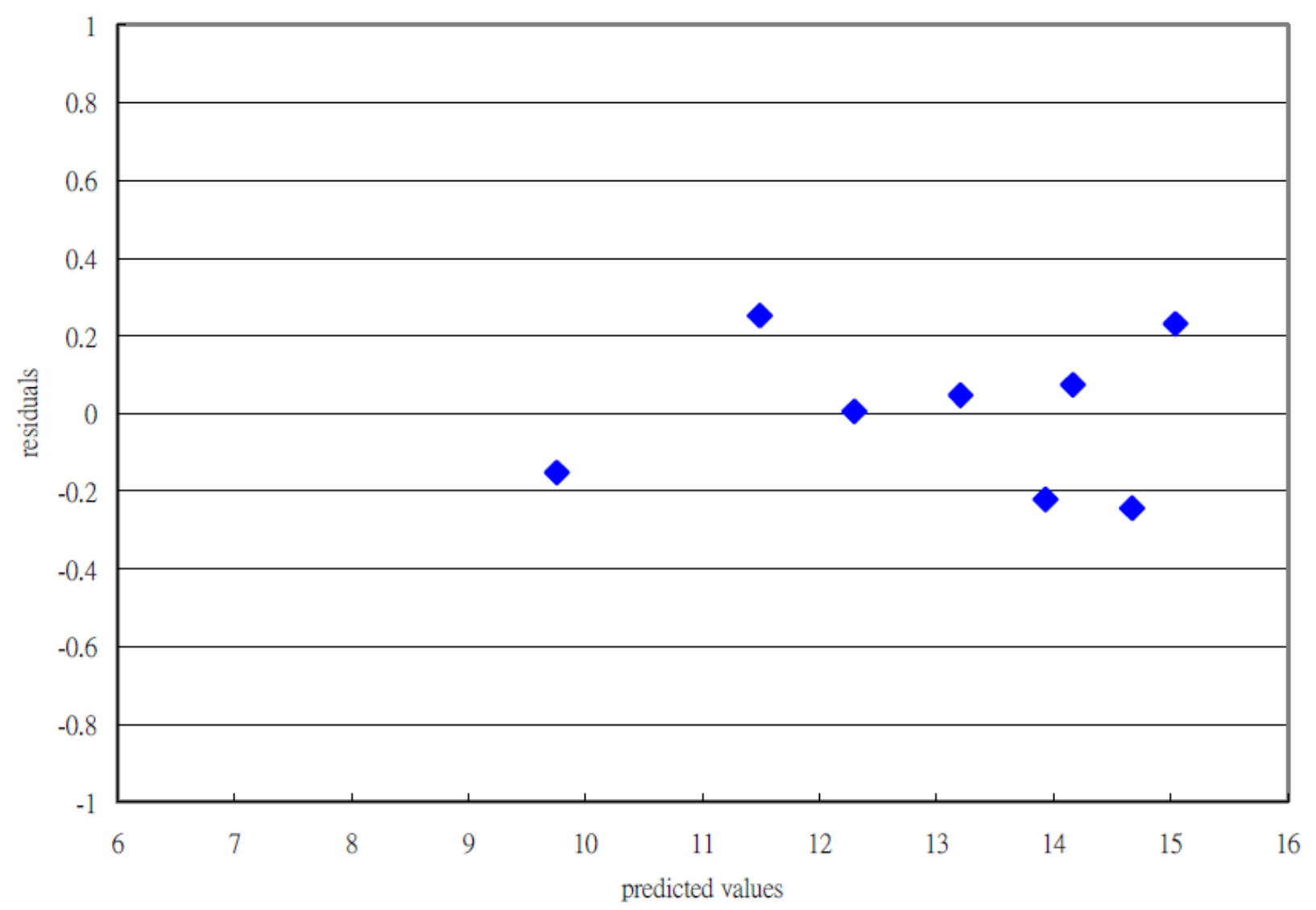

(2c) Tempkim equation

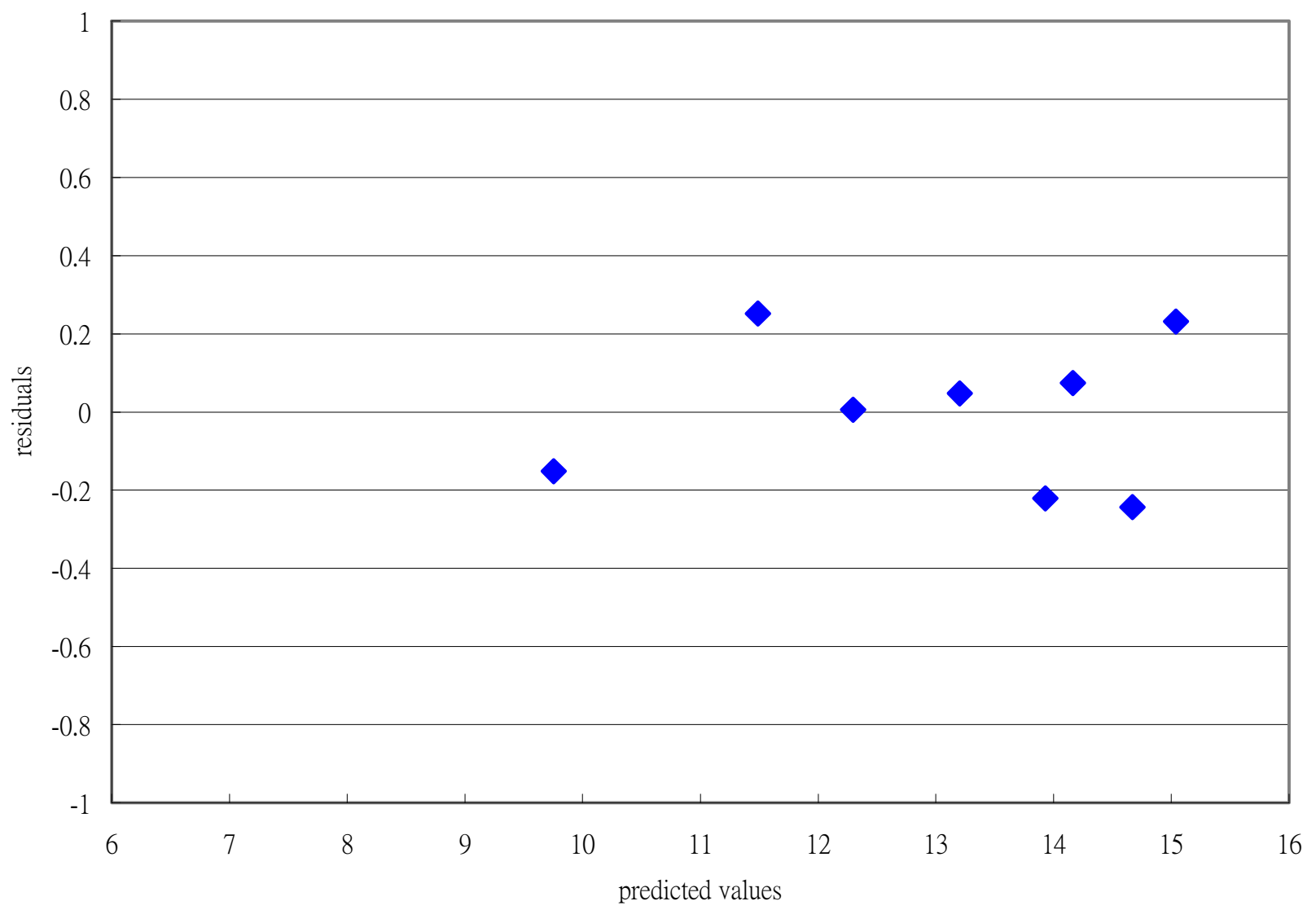

(2d) Redlich-Peterson equation 


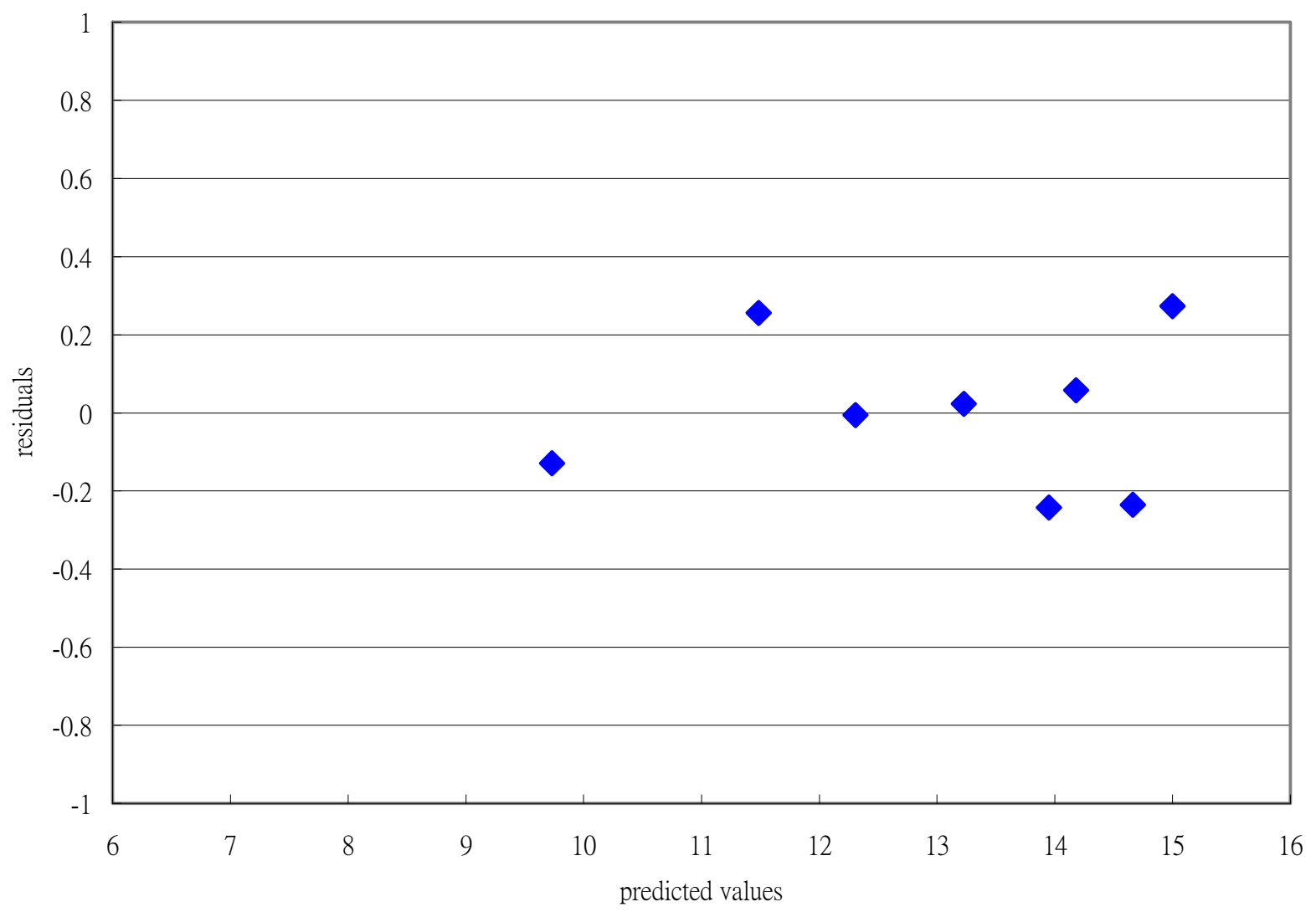

(2e) Hill equation

(2f) Toth equation

Fig. (2). (a-f). Residual plots of sorption isotherms for Ca by tree fern dor six isotherm equations.

With data from Ho [13] (Table 3), the Toth equation produced the highest $\mathrm{R}^{2}$ value and lowest $\mathrm{s}, \mathrm{ARE}, \mathrm{EABS}$ and MPSD values. However, the Hill equation produced the lowest HYBRID value. The equations produced inconsistent results for error functions, but residual plots revealed a uniform distribution for the three-parameter equations, RedlichPeterson, Hill and Toth equations.

For the Wang and Qin data [14] (Table 3), the Toth equation produced the highest $\mathrm{R}^{2}$ value and the Tempkim had the lowest $\mathrm{s}$ value. The Langmuir equation produced the lowest ARE, HYBRID, EABS and MPSD values. Residual plots revealed a clean pattern for only the Freundlich equation and a uniform distribution for the other five equations.

\subsection{Sorption Data for Three Metal Ions}

The isotherm constants and error functions for three metal ions from Mckay and Portor [7] are listed in Table 4.

For the $\mathrm{Cu}$ ion, the Hill equation produced the highest $\mathrm{R}^{2}$ value and the lowest EABS value. The Toth equation had the lowest HYBRID and MPSD values. The Redlich-Peterson equation produced lowest ARE value. The experimental data and predictive curves for the six equations are shown in Fig. (3) and the residual plots are presented in Fig. (4). Residual plots showed a clean pattern for the Freundlich and Langmuir equation and a uniform distribution for the Tempkim, Redlich-Peterson, Hill and Toth equation.
For the $\mathrm{Cd}$ ion, the Hill equation produced the highest $\mathrm{R}^{2}$ value and the lowest s, ARE, HYBRID, EABS and MPSD values. Residual plots showed a clean pattern for the twoparameter equations, Freundlich, Langmuir and Tempkim equations, and a uniform distribution for the three-parameter equations, Redlich-Peterson, Hill and Toth. For experimental datasets, the Hill equation could be the best equation to describe the relationship between adsorbate and adsorbent concentrations.

For the $\mathrm{Zn}$ ion, the Toth equation produced the highest $\mathrm{R}^{2}$ value and the Hill equation had the lowest EABS value. The Langmuir equation produced the lowest s, ARE, HYBRID and MPSD values. Residual plots showed the uniform distribution for four equations except the Freundlich and Tempkim equations.

\subsection{Effect of Temperature on Isotherm Data}

The data for ammonium biosorption by Posidonia oceanica seagrass fibers at five temperatures were from Wahab et al. [4]. The estimated constants and error functions are listed in Table 5. Residual plots showed the clean patterns for the Freundlich and Tempkim equation and the uniform distribution for other four equations (Fig. 5). However, the error functions showed inconsistent results. 


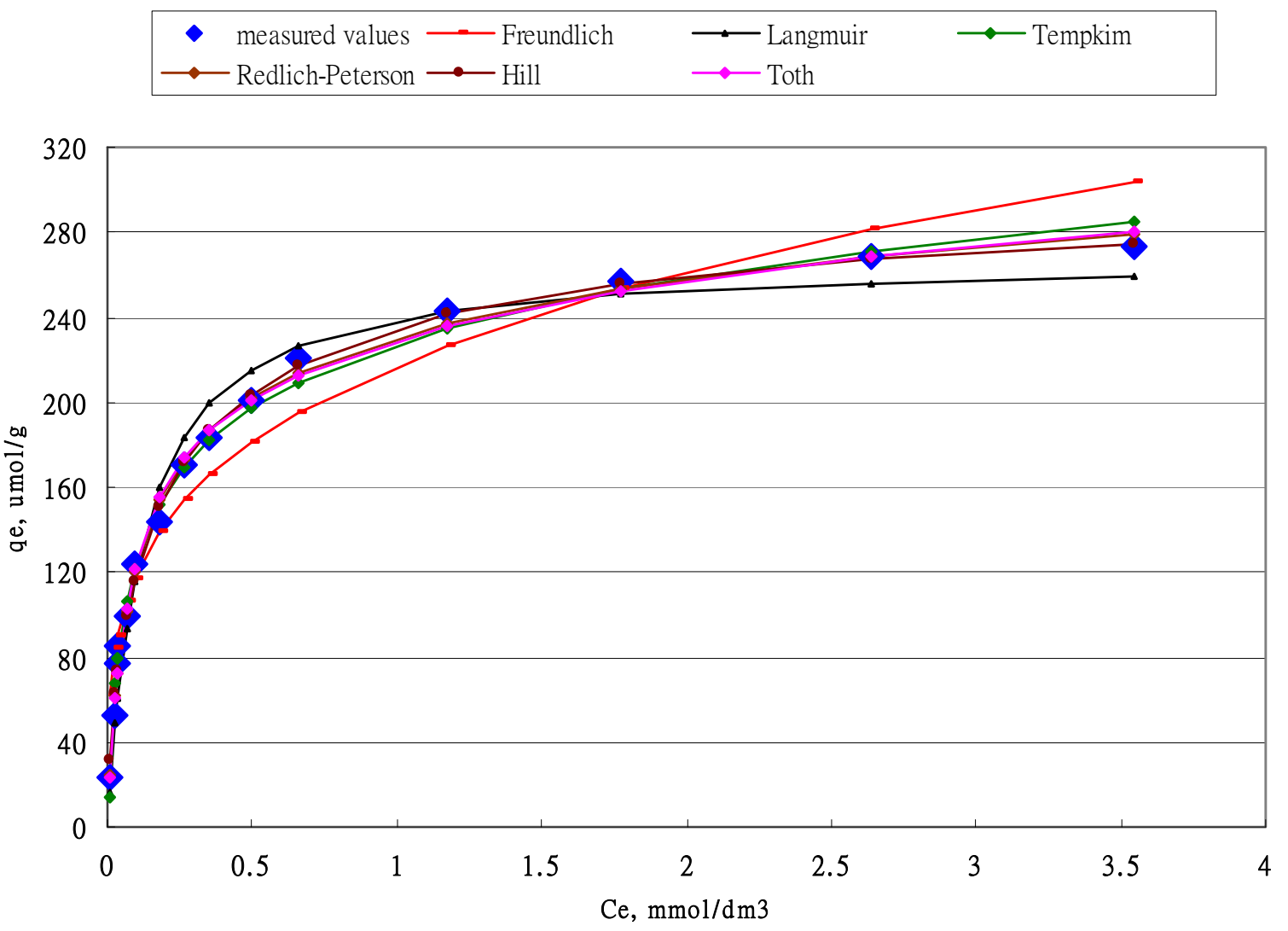

Fig. (3). Sorption isotherms for $\mathrm{Cu}$ by peat for six isotherm equations.

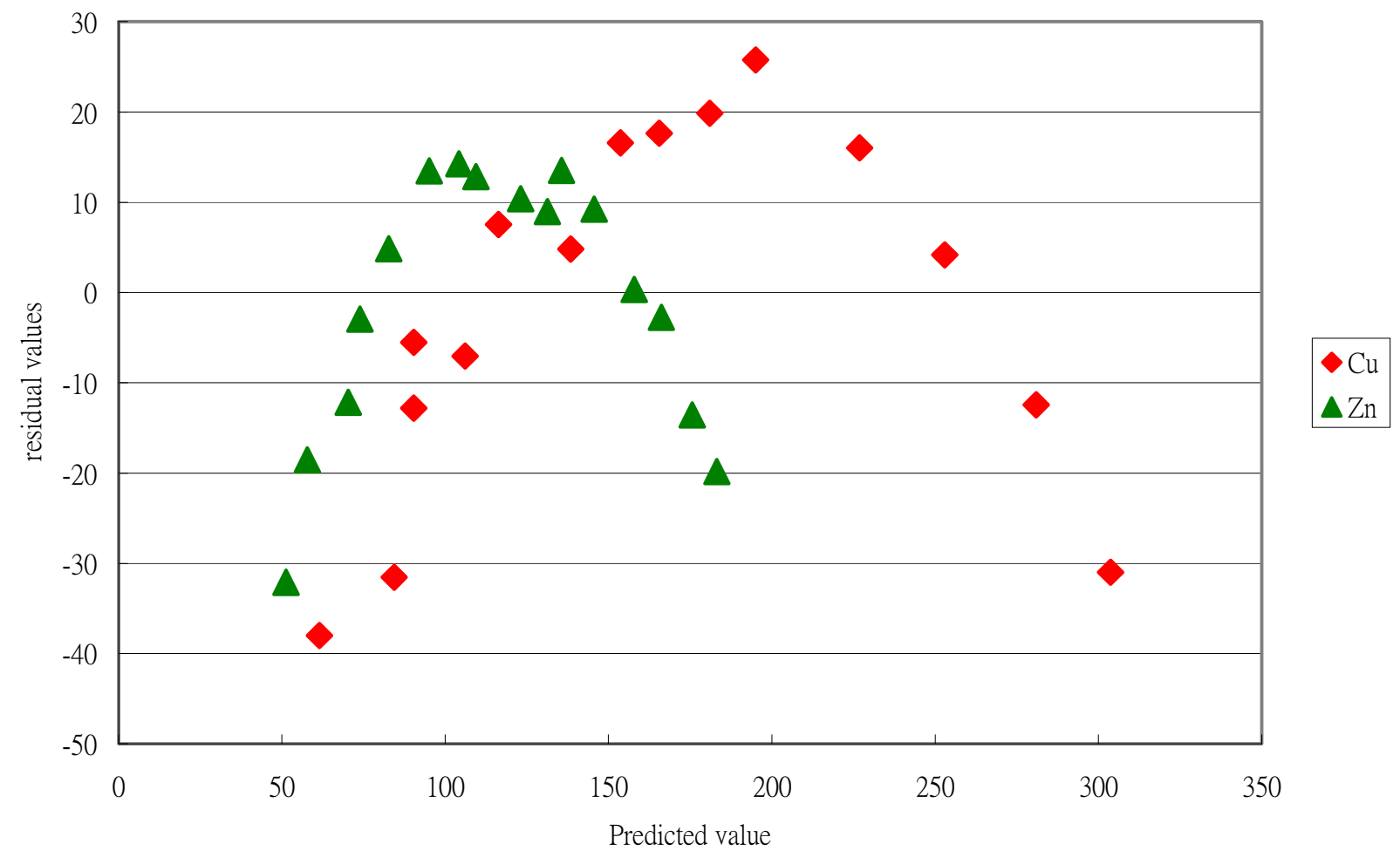

(4a) Freundlich equation 


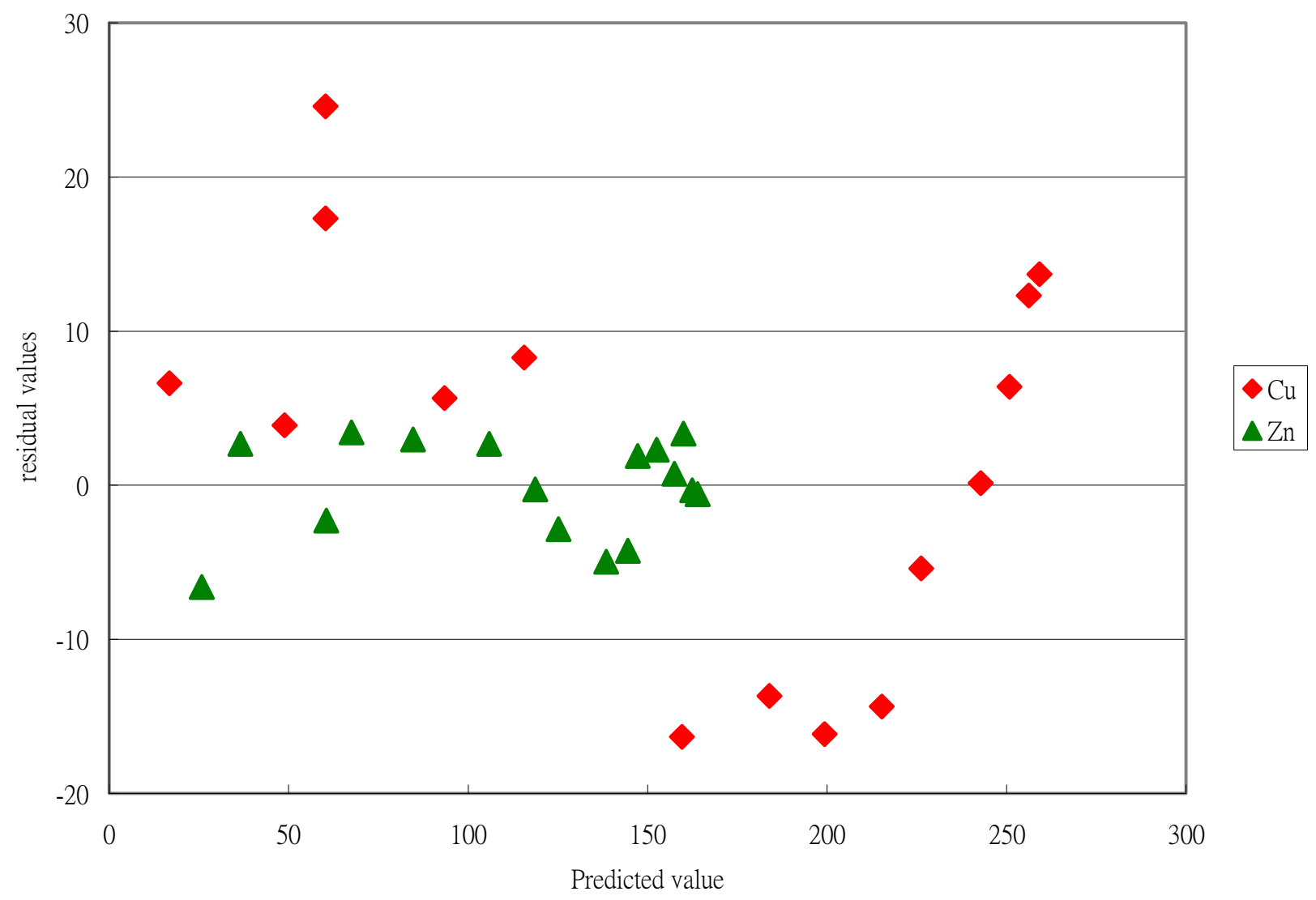

(4b) Langmuir equation

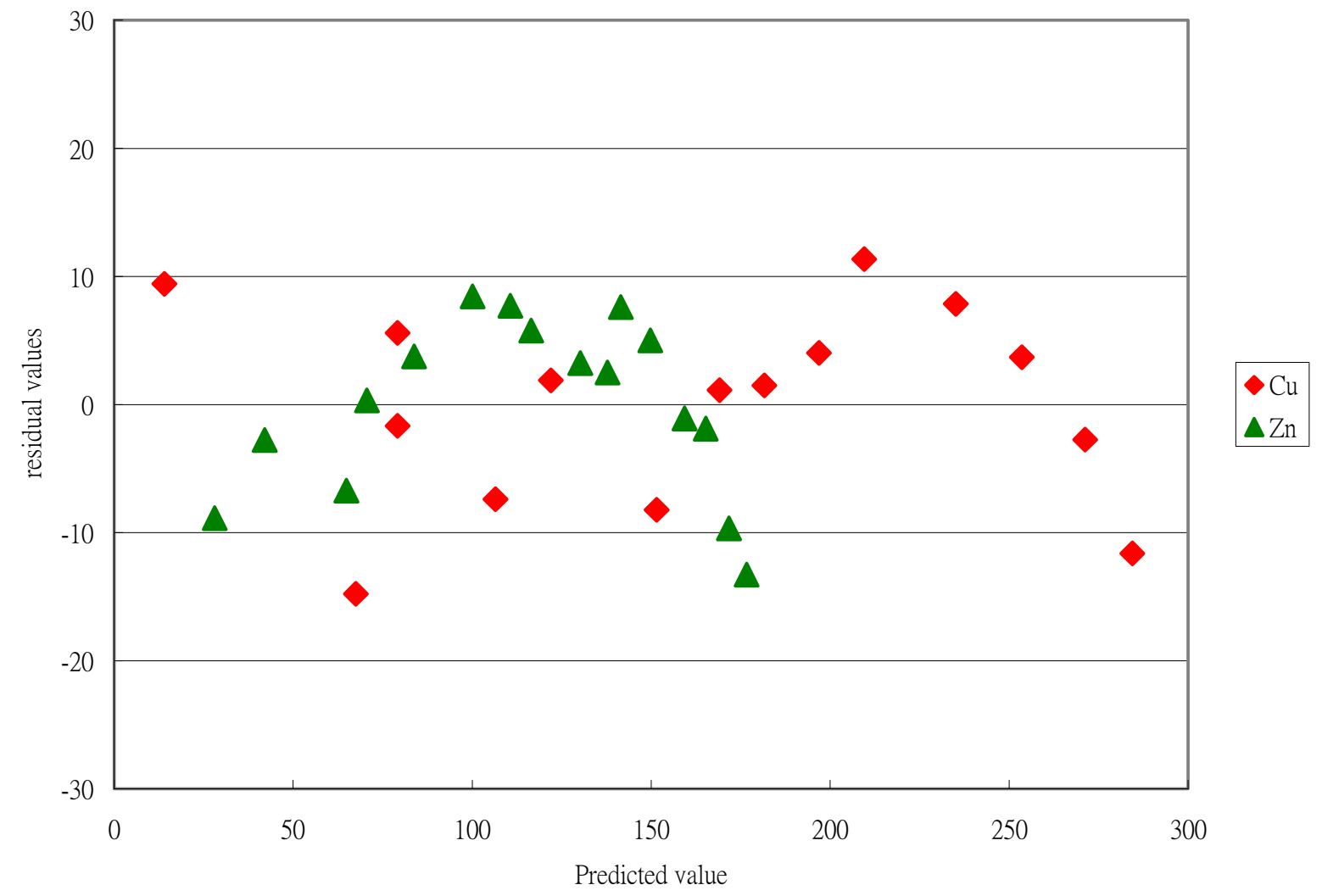

(4c) Tempkim equation 


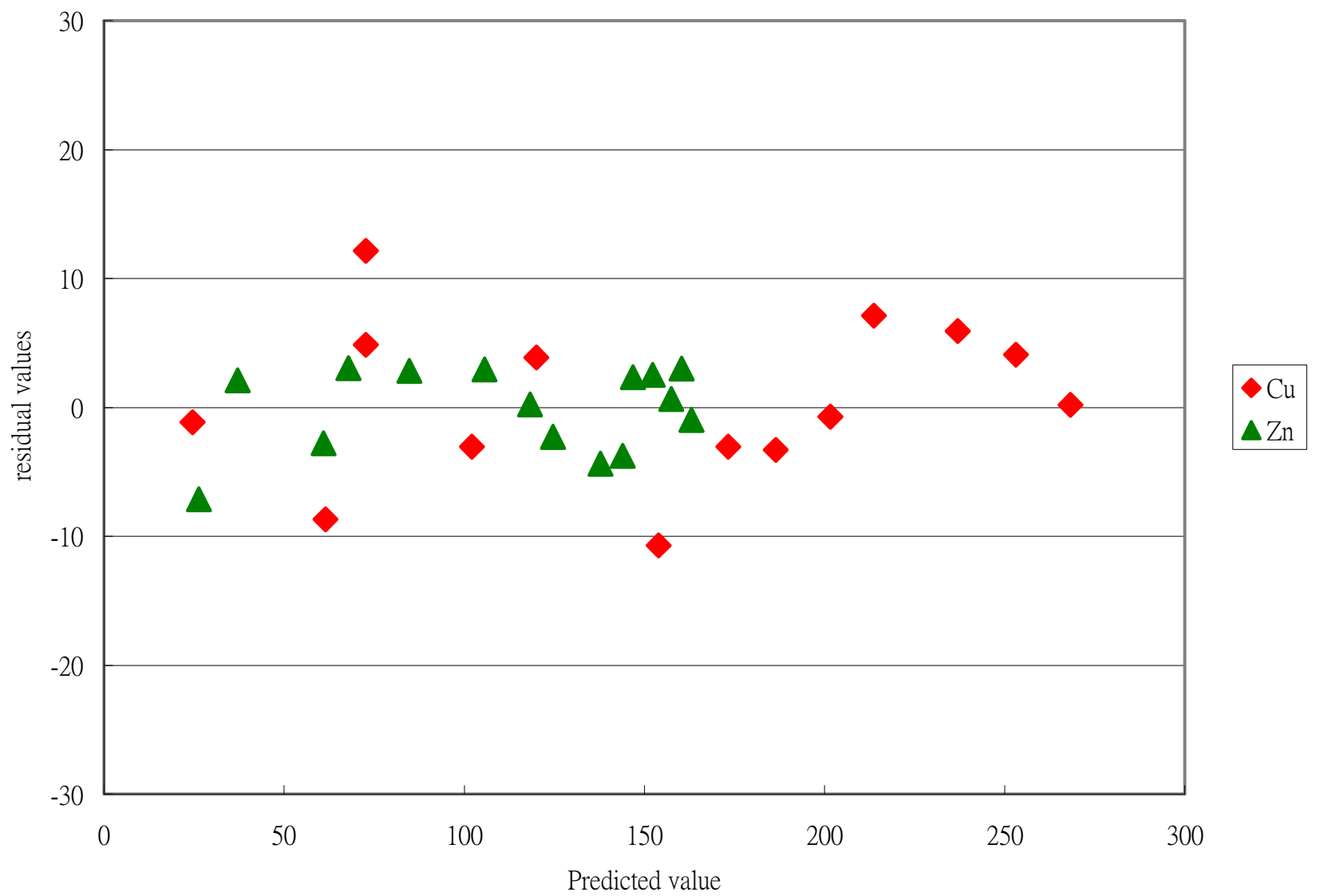

(4d) Redlich-Peterson equation

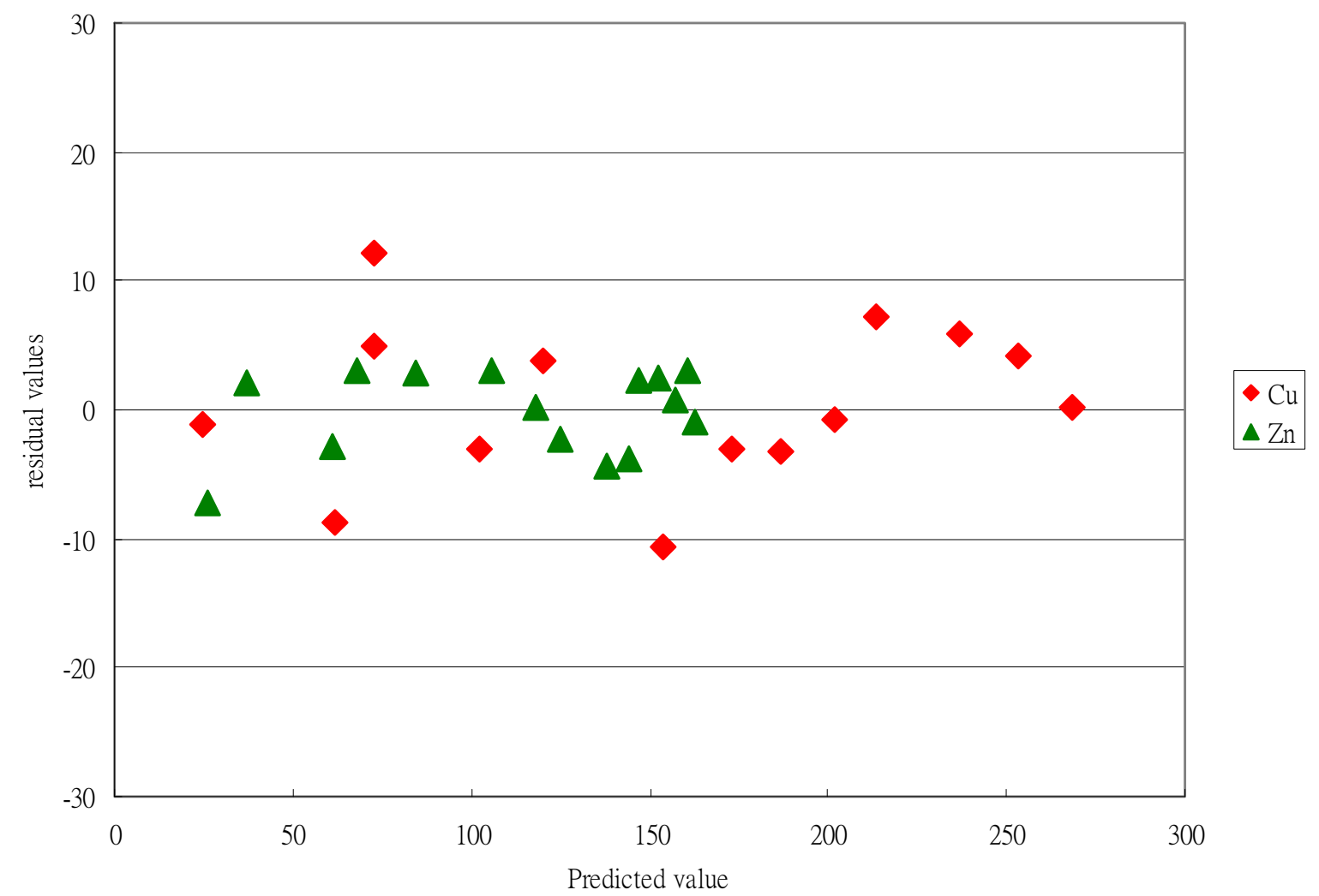

(4e) Hill equation 


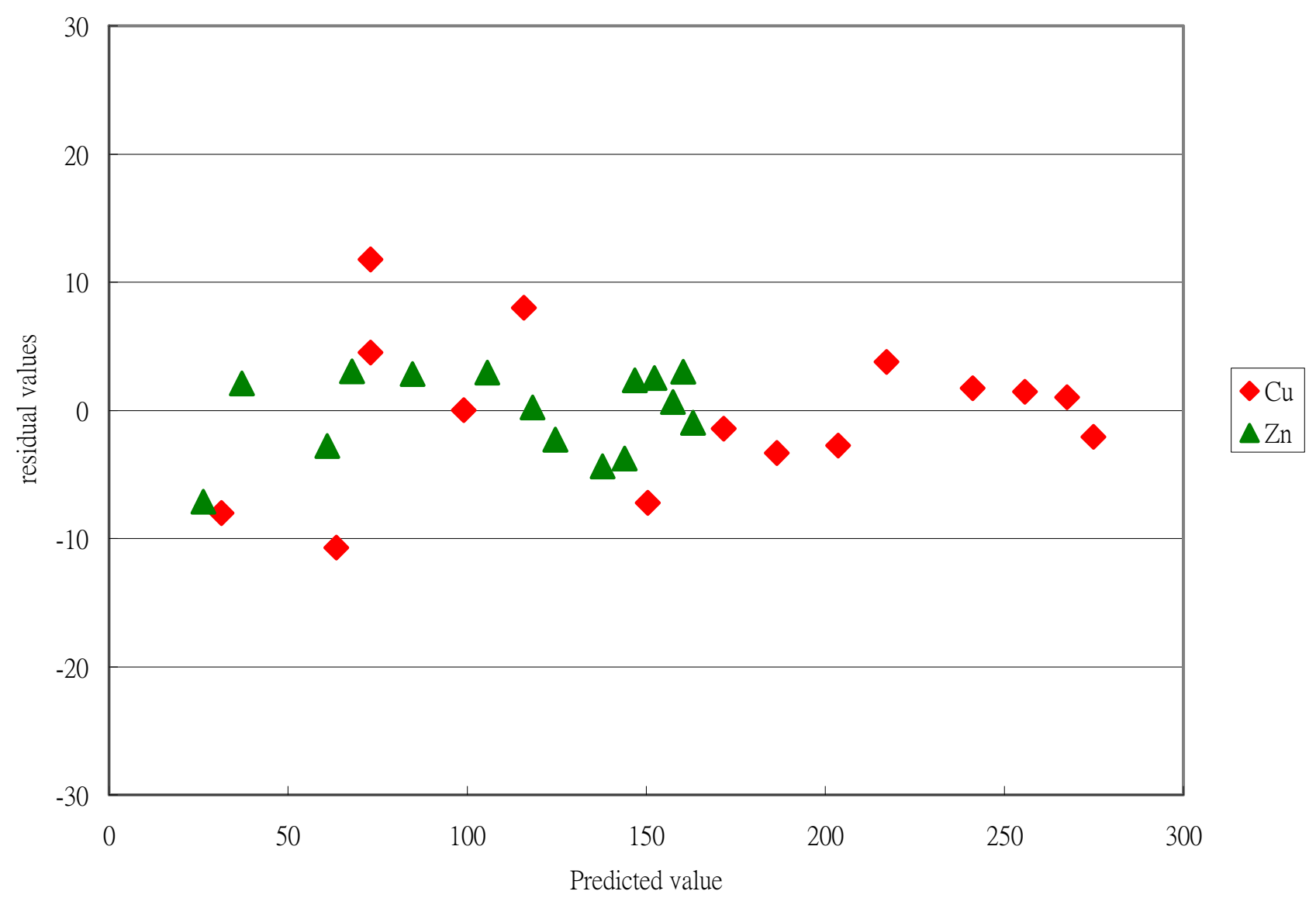

(4f) Toth equation

Fig. (4).(a-f) Residual plots of sorption isotherms for $\mathrm{Cu}$ by peat for six isotherm equations.

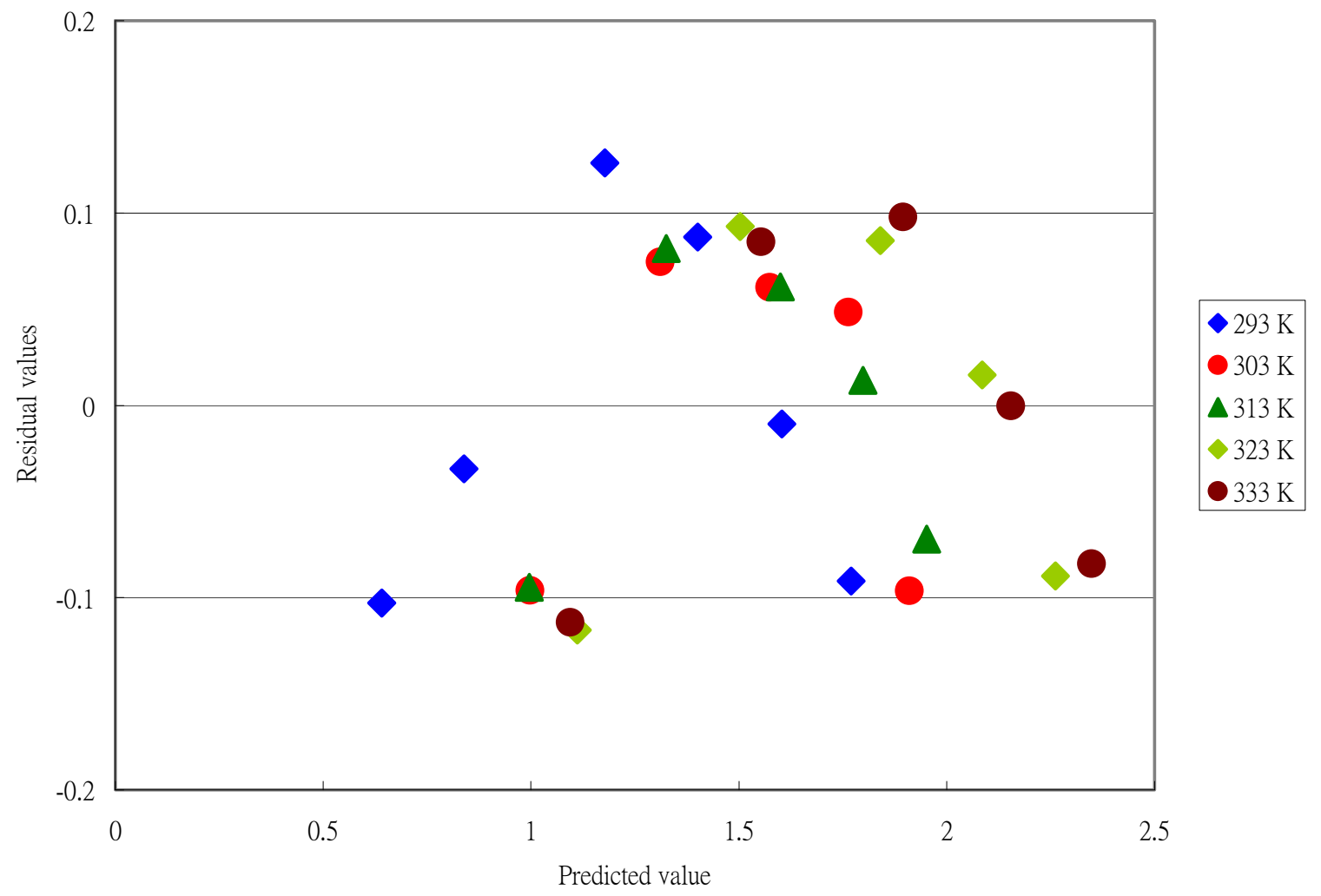

(5a) Freundlich equation 


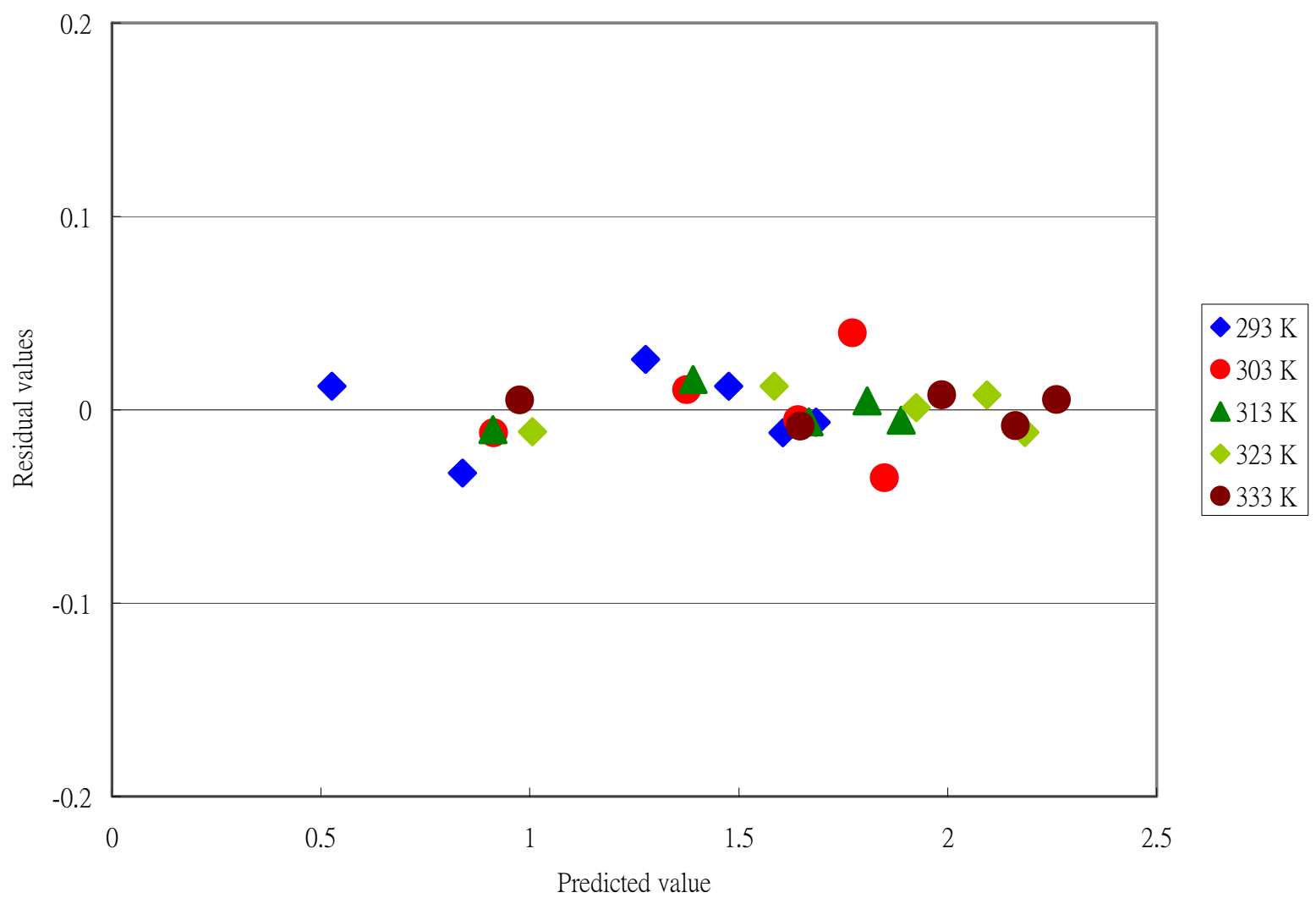

(5b) Langmuir equation

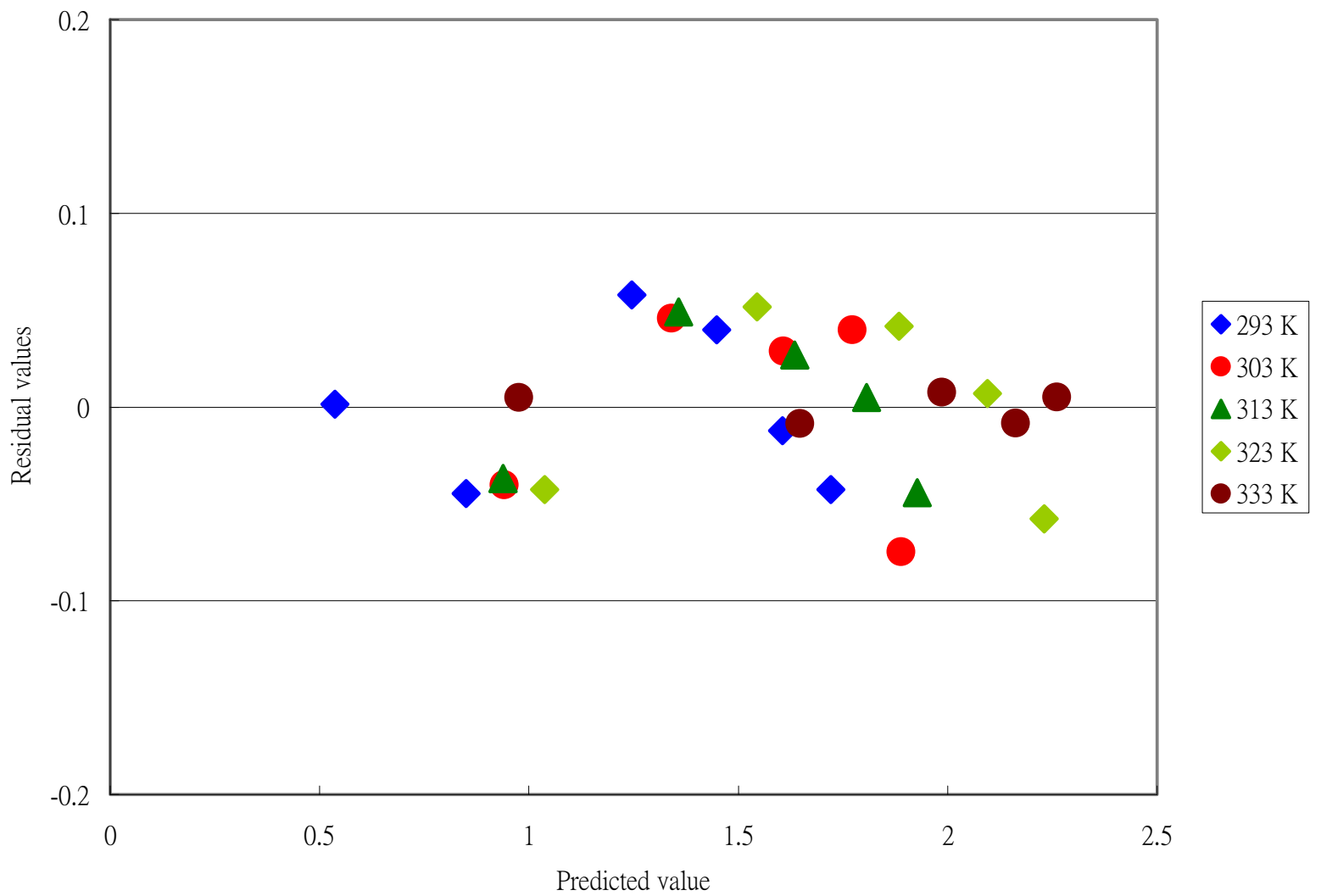

(5c) Tempkim equation 


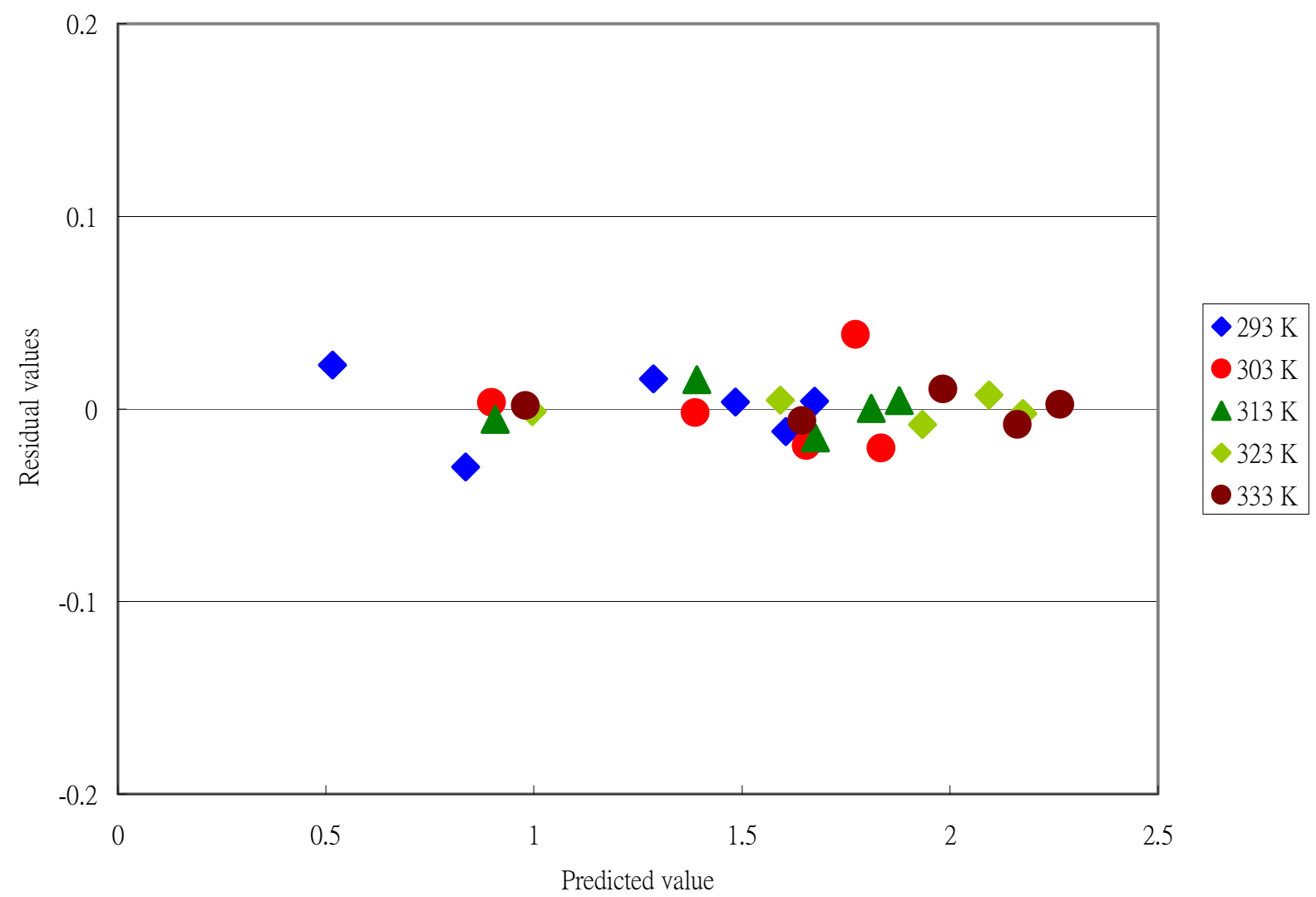

(5d) Redlich-Peterson equation

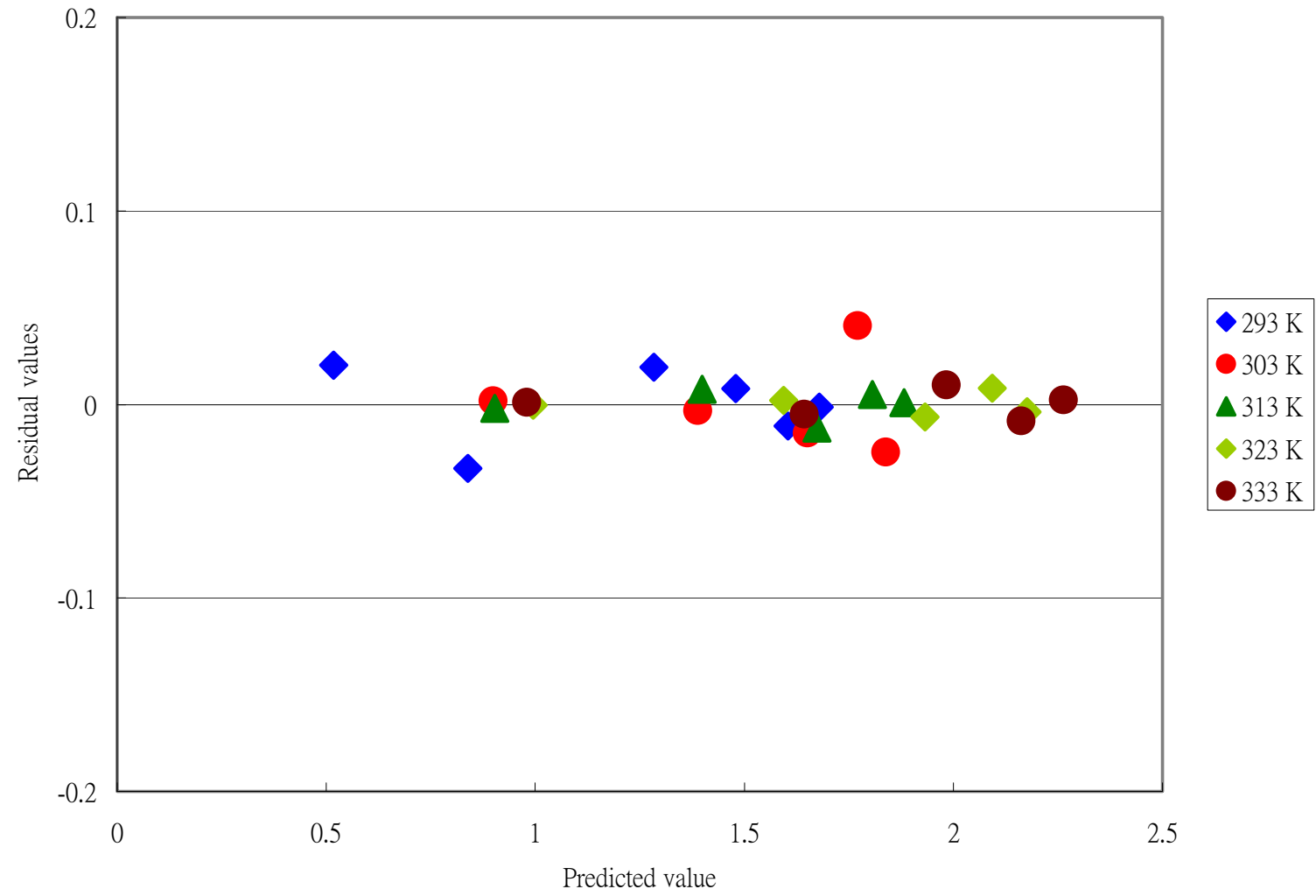

(5e) Hill equation 


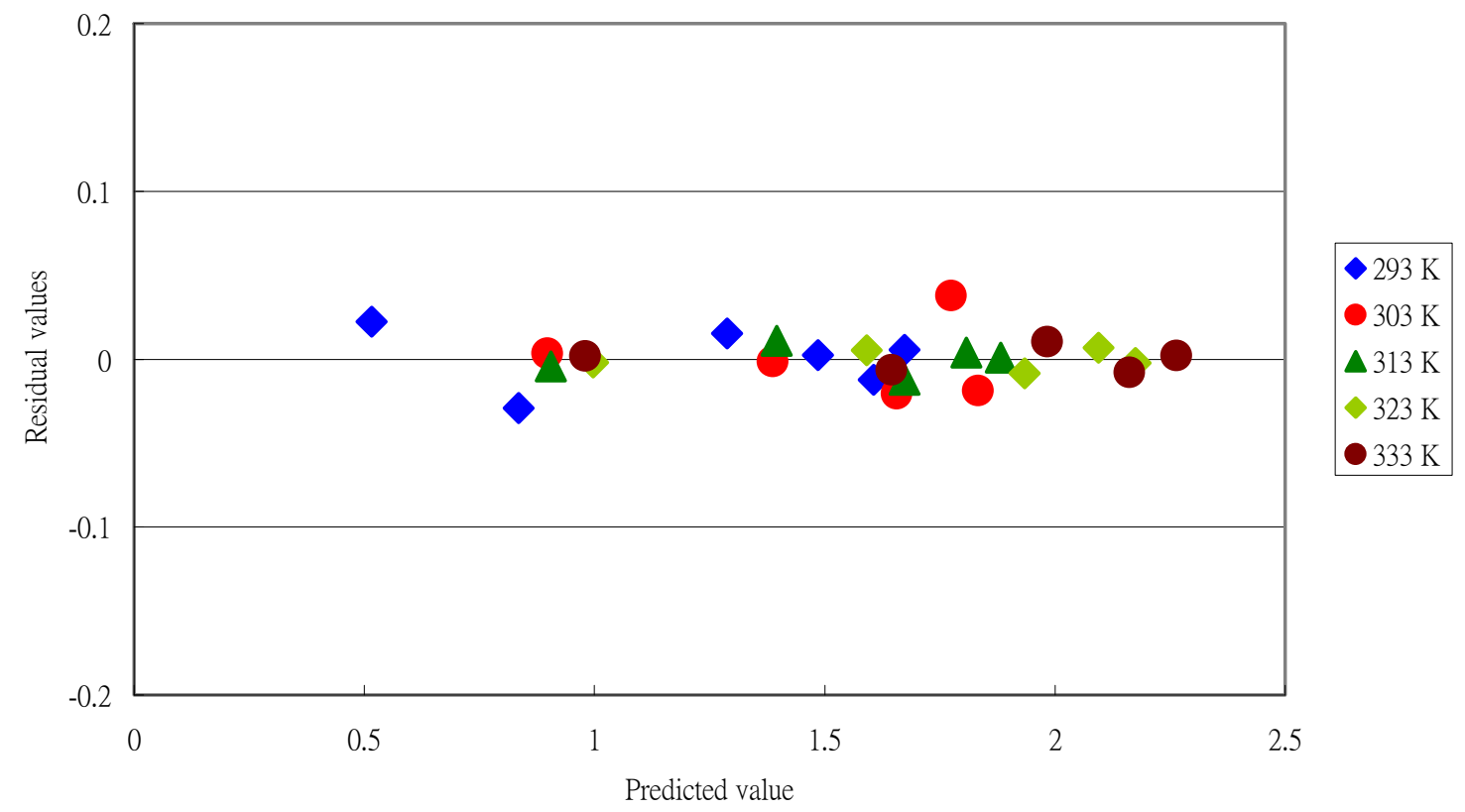

(5f) Toth equation

Fig. (5).(a-f) Residual plots of sorption isotherms for ammonium by Posidonia Oceanica seagrass fibers at five temperatures using six isotherm equations.

Table 4. Isotherm Constants and Error Functions for Six Isotherm Equations with Data for Three Metal Ions from Mckay and Porter [7]

\begin{tabular}{|c|c|c|c|c|c|c|}
\hline Metal ion & Freundlich & Langmuir & Tempkim & Redlich Peterson & Hill & Toth \\
\hline \multicolumn{7}{|l|}{$\mathrm{Cu}$} \\
\hline B & 0.2628 & 0.1213 & 44.4797 & 0.8826 & 0.6841 & 0.8669 \\
\hline $\mathrm{C}$ & & & & 6.06704 & 0.3333 & 0.0484 \\
\hline s & 21.1158 & 13.5671 & 8.0094 & 6.8069 & $\underline{6.4430}$ & 7.0975 \\
\hline ARE & 21.7823 & 11.4839 & 7.3508 & $\underline{4.6260}$ & 6.2507 & 4.3841 \\
\hline HYBRID & 25.1335 & 13.2506 & 8.4817 & 8.3268 & 7.8133 & $\underline{5.0585}$ \\
\hline EABS & 250.6866 & 164.7886 & 92.8681 & 75.6685 & $\underline{64.7468}$ & 77.6173 \\
\hline \multicolumn{7}{|l|}{$\mathrm{Cd}$} \\
\hline A & 14.5924 & 18.3504 & 15.2445 & 16.705 & 20.5359 & 16.4531 \\
\hline B & 0.2331 & 0.1322 & 2.7837 & 0.9079 & 0.6944 & 0.8993 \\
\hline $\mathrm{C}$ & & & & 0.07409 & 0.2992 & 0.06110 \\
\hline $\mathrm{R}^{2}$ & 0.9318 & 0.9782 & 0.9798 & 0.9878 & 0.9942 & 0.9864 \\
\hline s & 1.4358 & 0.8116 & 0.7811 & 0.6308 & $\underline{0.4331}$ & 0.6659 \\
\hline ARE & 16.5813 & 10.2970 & 7.9223 & 6.4250 & $\underline{3.4502}$ & 6.9750 \\
\hline
\end{tabular}


Table 4 Contd.....

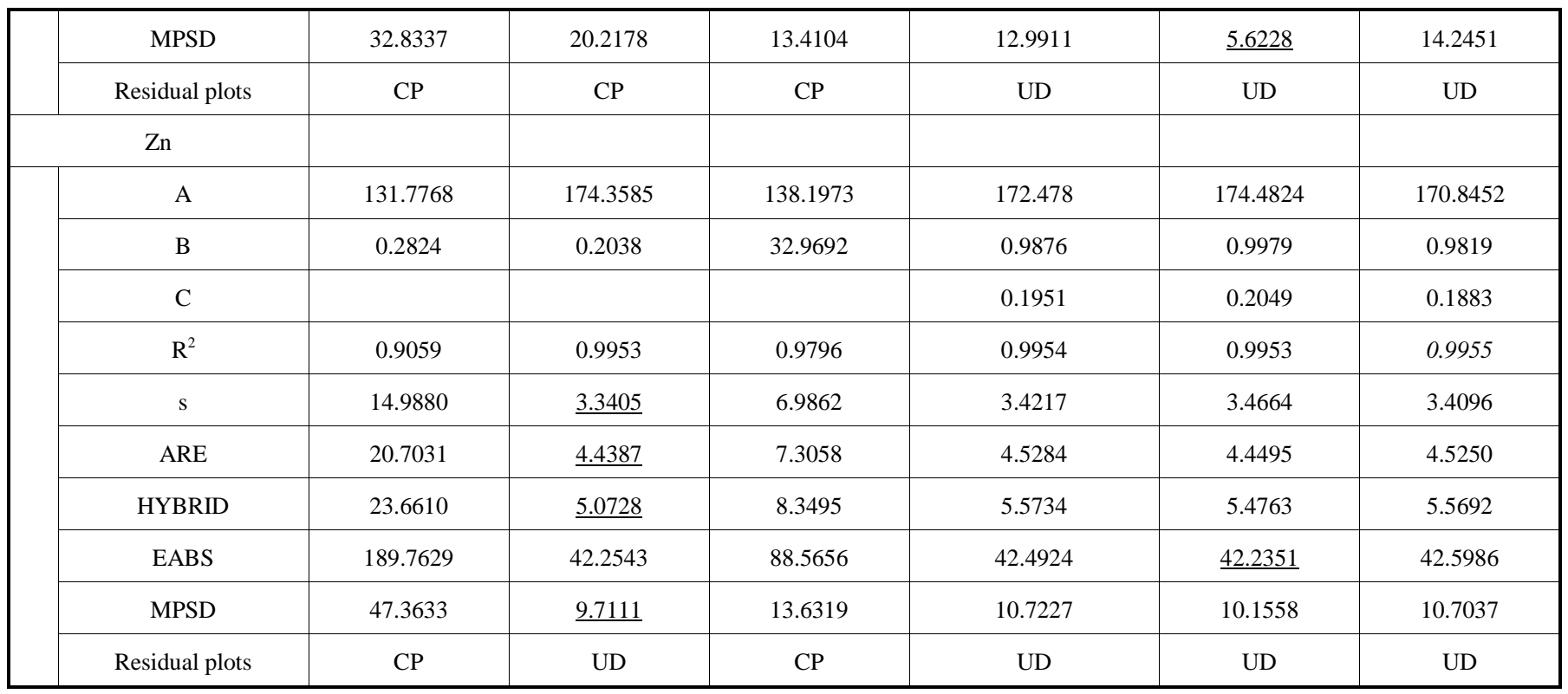

Table 5. Isotherm Constants and Error Functions for Six Isotherm Equations with Data for Five Temperatures from Wahab et al. [4])

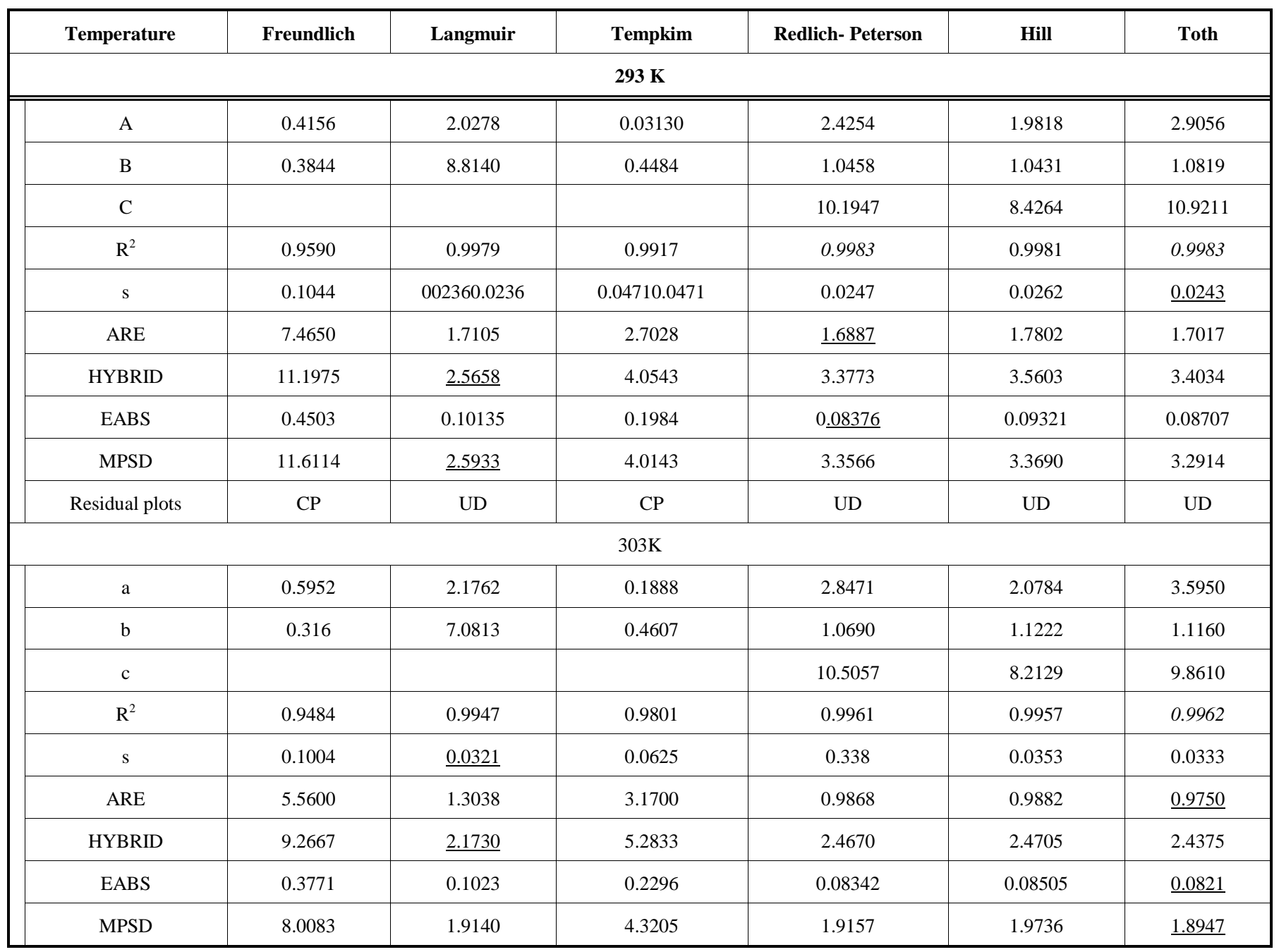


Table 5 Contd.....

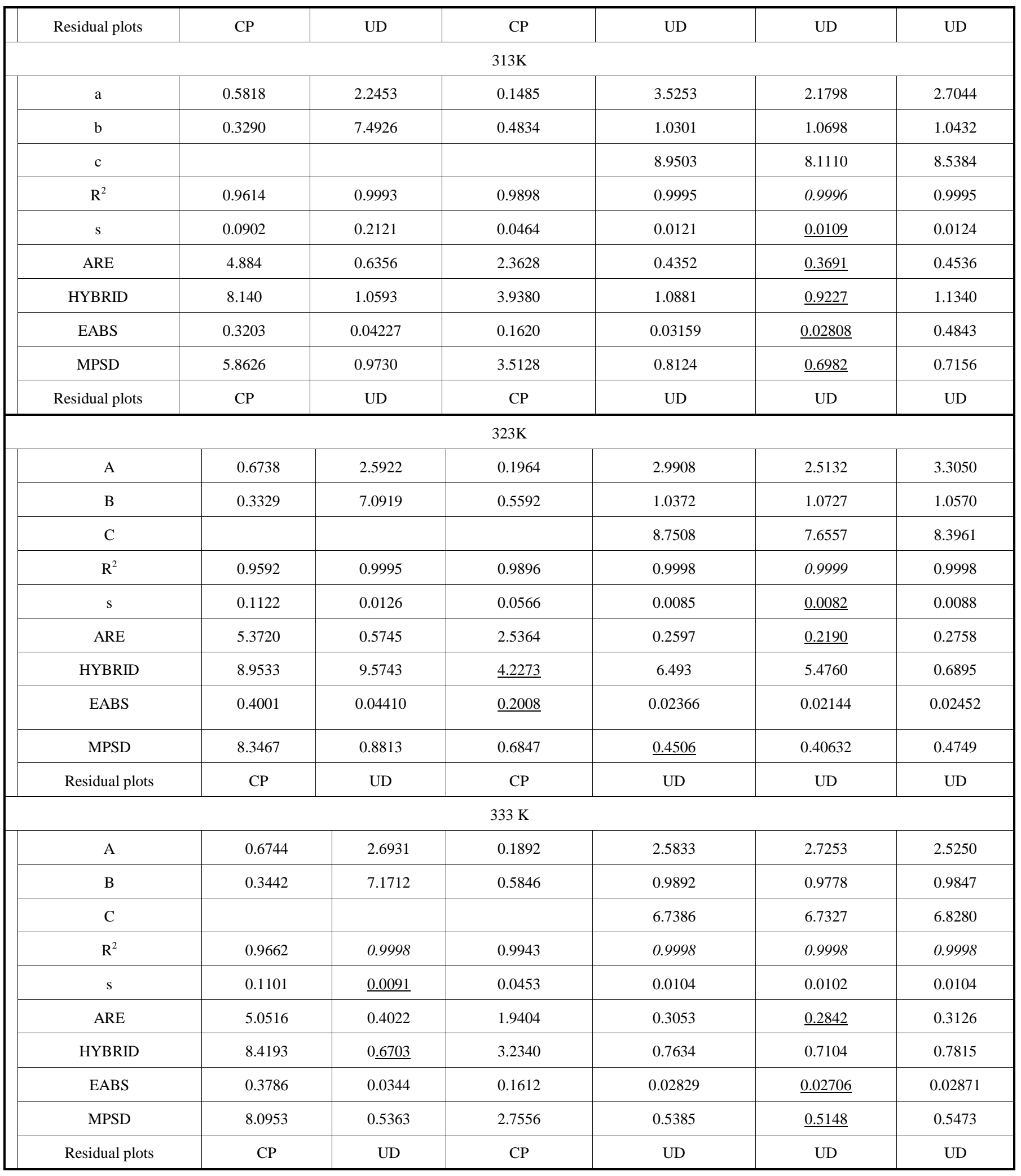

For the $293 \mathrm{~K}$ temperature data, the Redlich-Peterson and Toth equation produced the same $\mathrm{R}^{2}$ values. The Toth equation had the lowest s value and the Redlich-Peterson equation had the lowest ARE and EABS values. The Langmuir equation had the lowest HYBRID and MPSD values.
For the $303 \mathrm{~K}$ temperature data, the Toth equation had the highest $R^{2}$ value and lowest ARE, EABS and MPSD values and the Langmuir equation had the lowest $s$ and HYBRID values. 
For the $313 \mathrm{~K}$ temperature data, the Hill equation could be the best fitting ability, it had the highest $\mathrm{R}^{2}$ value and lowest value for other criteria.

For the $323 \mathrm{~K}$ and $333 \mathrm{~K}$ temperature data, results for error functions were inconsistent.

The isotherm constants of Langmuir and Hill equations were used to study the effect of temperature on sorption isotherms (Fig. 6). Temperature was significantly associated with $\mathrm{k}_{\mathrm{L}}$ and $\mathrm{a}_{\mathrm{L}}$ of the Langmuir equation and $\mathrm{q}_{\mathrm{SH}}$ and $\mathrm{k}_{\mathrm{D}}$ but not $\mathrm{nH}$ of the Hill equation.

In the study of the sorption isotherm for metal ions on tree fern, the experiments were tested at four temperatures [6]. Temperature was significantly associated with $\mathrm{k}_{\mathrm{L}}$ and $\mathrm{a}_{\mathrm{L}}$ of the Langmuir isotherm were listed. The results were similar as this study.

Many sorption isotherm equations are nonlinear equations. Linearization methods had been adopted to transform dependent and independent variables for linear regression analysis. The problems have been reviewed [16].

The Langmuir isotherm equation was used to demonstrate the expanded variance of constants with linearization [23]. EI-Khaiary et al. [17] analyzed simulated data by nonlinear regression and four linearized forms of the pseudosecond-order equation. Nonlinear regression had the minimum variance and was considered the most accurate methods. The current study compared three two-parameter and other three three-parameter isotherm equations analyzed with the nonlinear regression analysis. Six error functions were

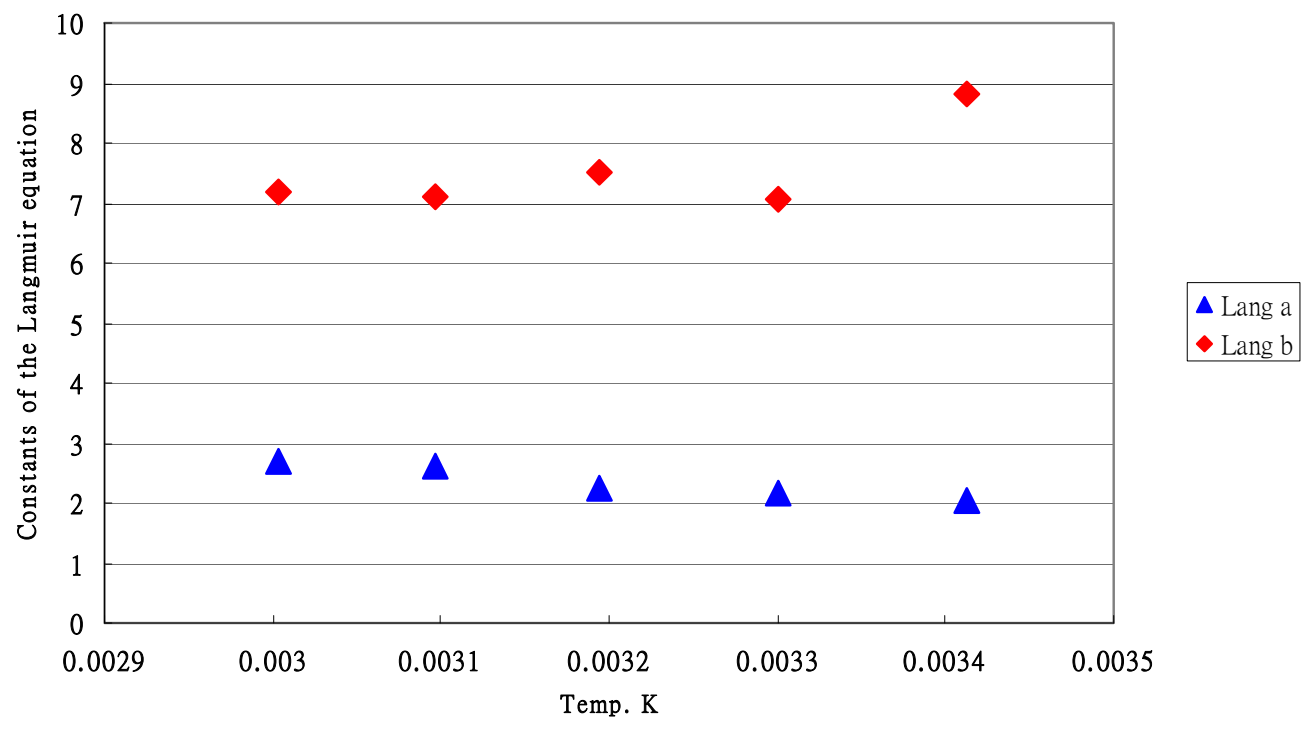

(6a) Langmuir equation

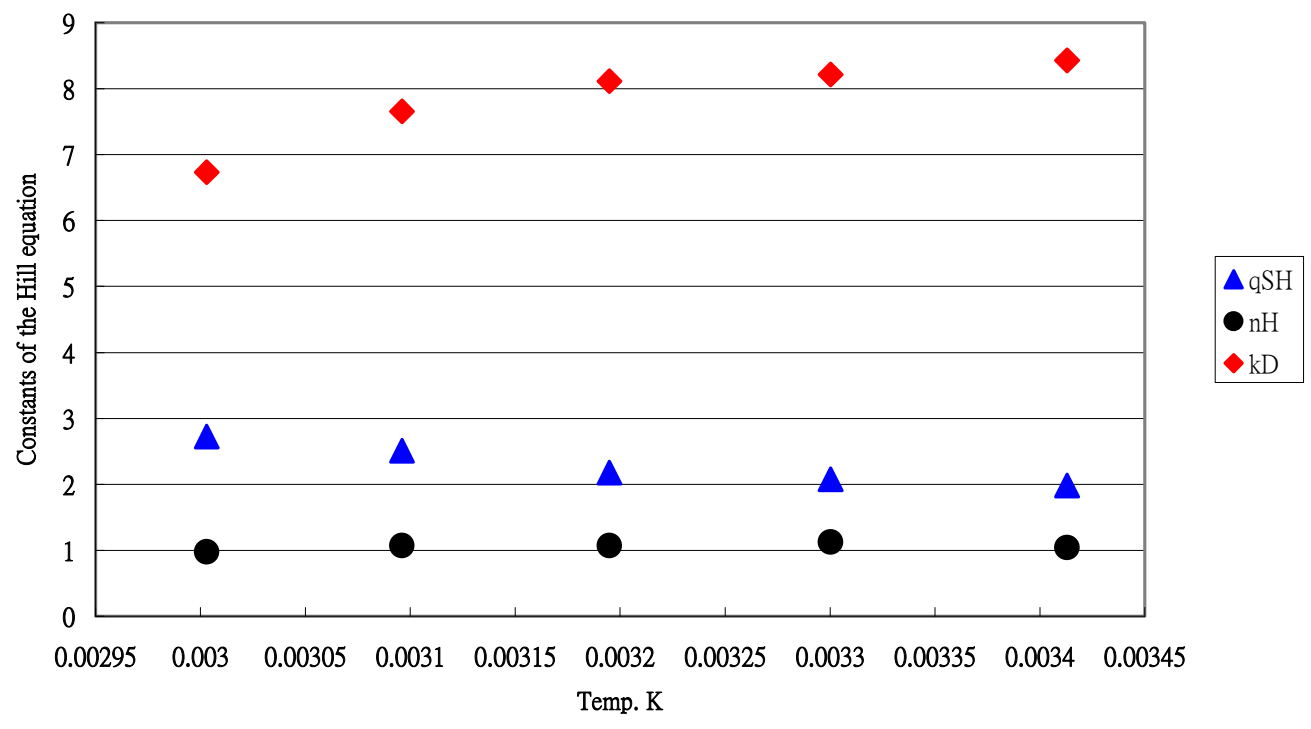

(6b) Hill equation

Fig. (6).(a-b) Effect of temperature on constants of two isotherm equations. 
selected to compare the fitting-agreement of isotherm equations. The inconsistent results were found. Only the Hill equation produced the lowest values for all error functions for $\mathrm{Cd}$ ions. For most data, no isotherm equation produced all the low values for errors functions. Similar results can be found in the literatures. Five isotherm equations were selected to study adsorption of two basic dyes by kudzu [11], the linear-transformed Redlich-Peterson equation produced the highest $\mathrm{R}^{2}$ value, but did not have the lowest values for the other error functions.

Seven isotherm equations were tested for toxin adsorption with yeast biomass [8]. For OA adsorption by EX16 yeast biomass, the Hill equation produced the lowest values for the six error functions. For OA adsorption by betaglucanes, the Hill equation had the lowest MPSD, ARE and the sum of normalized errors (SNE). However, the Toth equation produced the lowest HYBRID and EABS values and the BET equation had the lowest sum of the squares of errors (ERRSQ). Inconsistent results were found for OA adsorption by a yeast cell wall fraction (LEC).

A new error function, the small-sample-corrected Akaike information criterion (AICc) was proposed to evaluate seven isotherm equations [15]. The Freundlich equation best described the adsorption of $\mathrm{Cu}^{2+}$ and $\mathrm{Cd}^{2+}$ data by Bentonite adsorbents. However, the HYBRD, ARE, MPSD and EABS values for the Freundlich equation were higher than for other isotherm equation such as Langmuir, Redlich-Peterson and Sip.

Results were inconsistent in evaluating the predictive ability of isotherm equations for adsorption of textile dye by Posidonia oceanica seagrass fibres [22]. The RedlichPeterson equation had highest $\mathrm{R}^{2}$ value and the lowest ARE, MPSD, HYBRID, ERRSQ and s values. However, this equation had the highest values by Students $t$ test.

Researchers have plotted the data distribution of the amount of ion sorbed $\left(\mathrm{q}_{\mathrm{e}}\right)$ versus the isotherm equilibrium concentration $\left(\mathrm{C}_{\mathrm{e}}\right)$ and the predictive curves of several isotherm equations were used by researchers $[2,6,8,12-14,18]$. However, the fitting ability is not easily justified visually. In this study, residual plots were dfound to be an adequate quantitative evaluation method. As the model is inadequate, the predictive values were under-or over-estimated. The inadequate results are easy to observe with the data distribution of residual plots.

The effect of the temperature on sorption isotherms has been analyzed [4-6,24]. In this study, with data from Wahab et al. [4], temperature was associated with constants of the Langmuir equation and two constants of the Hill equation. The effect of the temperature on constants could be expressed as a temperature function and then incorporated into isotherm equations to express the relationship among $\mathrm{C}_{\mathrm{e}}, \mathrm{q}_{\mathrm{e}}$, and temperature. The development and validations of an adequate isotherm equations incorporating a temperature term remains for further studied.

\section{CONCULSION}

This study used eleven datasets from the literatures to assess the fitting ability of sorption isotherm equations in determining the capacity of an adsorption system to treat industrial wastewater. Nonlinear regression analysis was used to avoid problems with linearization which alters the error distribution and distorts the variance structure. Results for error functions were inconsistent among sorption isotherms, but residual plots were useful to observe the fitting ability of isotherm equations. Temperature had a significant effect on the constants of isotherms. Incorporating a temperature term into isotherm equations needs further study.

\section{CONFLICT OF INTEREST}

The author has none to declare.

\section{ACKNOWLEDGEMENTS}

The authors would like to thank the National Science Council of the Republic of China for financially supporting this research under Contract No. 98-2313-B-005-032-MY3.

\section{REFERENCES}

[1] S. Al-Asheh, F. Banat, R. Al-Omari, and Z. Duvanjak, "Predictions of binary sorption isotherms for the sorption of heavy metals by pine bark using single isotherm data", Chemosphere, vol.41, pp. 659-665, 2003.

[2] Y.S. Ho, J.F. Porter, and G. Mckay, "Equilibrium isotherm studies for the sorption of divalent metal ions onto peat: copper, nickel and lead single component systems", Water Air Soil Poll. vol. 141, pp.1-33, 2002.

[3] G. Vazquez, J. Gonzalez-Alvarez, S. Freire, M. Lopez-Lorenzo, and G. Antorrena, "Remove of cadmium and mercury ions from aqueous solution by sorption on treated Pinus pinaster bark: kinetics and isotherms", Bioresource Technol. Vol. 82, pp. 247-251, 2002.

[4] M.A. Wahab, S. Jellali, and N. Jedidi, "Effect of temperature and $\mathrm{pH}$ on the biosorption of ammonium onto Posidonia oceanica fibers: Equilibrium, and kinetic modeling studies", Bioresource Technol. Vol.101, pp. 8606-8615, 2010.

[5] A.E. Ofomaja, and Y. Ho, "Effect of temperatures and $\mathrm{pH}$ on methyl violet biosorption by Mansonia wood sawdust", Bioresource Technol., vol. 99, pp. 5411-5417, 2008.

[6] Y.S. Ho, C.T. Huang, and H.W. Huang, "Equilibrium sorption isotherm for metal ions on tree fern", Process Biochem., vol. 37 pp. 1421-1430, 2002.

[7] G. Mckay, and J.F. Porter, "A comparison of Langmuir based models for predicting multicomponent metal ion equilibrium sorption isotherms on peat", Trans. IChem. E., vol. 75B, pp. 171-180, 1997.

[8] D. Ringot, B.L. Lerzy, K. Chaplain, J. Bonhoure, E. Auclair, and Y. Larondelle, "In vitro biosorption of ochratoxin A on the yeast industry by-products: Comparison of isotherm models", Bioresource Technol., vol. 98, pp. 1812-1821, 2007.

[9] K.Y. Foo, and B.H. Hameed, "Insights into the modeling of adsorption isotherm systems", Chem. Eng. J., vol.156, pp.2-10, 2010.

[10] Y. Liu, and Z. Wang, "Uncertainty of pseset-order kinetic equations in description of biosorption data", Bioresource Technol., vol. 99, pp. 3309-3312, 2008.

[11] S. Allen, Q. Gan, R. Matthews, and P.A. Johnson, "Comparison of optimized isotherm models for basic dye adsorption by kudzu", Bioresource Technol., vol. 88, pp. 143-152, 2003.

[12] Y. Ho, and C.C. Wang, "Pseudo-isotherms for the sorption of cadmium ion onto tree fern", Process Biochem., vol. 39, pp. 759-763, 2004.

[13] Y.S. Ho, "Selection of optimum sorption isotherm", Carbon, vol. 42, pp. 2113-2130, 2004

[14] X. Wang, and Y. Qin, "Equilibrium sorption isotherms for of $\mathrm{Cu}^{2+}$ on rice bran", Process Biochem., vol. 40, pp. 677-680, 2005.

[15] O.M., Akpa, and E.I. Unuabonah, "Small-sample corrected Akaike information criterion: an appropriate statistical tool for ranking of adsorption isotherm models", Desalination, vol. 272, pp. 20-26, 2006. 
[16] M.I. EI-Khaiary, and G.F. Malash, "Common data analysis errors in batch adsorption studies", Hydrometallurgy, vol. 105, pp. 314320,2010

[17] M.I. EI-Khaiary, G.F. Malash, and Y. Ho, "On the use of linearized psedudo-second-order kinetic equations for modeling adsorption systems", Desalination, vol. 257, pp. 93-101, 2007.

[18] S. Parimal, M. Prasad, and U. Bhaskar, "Prediction of equilibrium sorption isotherm: Comparison of linear and nonlinear methods", Ind. Eng. Chem. Res., vol. 49, pp. 2882-2888, 2010.

[19] N.R. Draper, and H. Smith, "Applied Regression Analysis". $2^{\text {nd }}$ ed., Wiley: New York, 1981

[20] R.H. Myers, "Classical and Modern Regression with Application", PWS and Kent Publisher: New York, 1986.
[21] M.I. EI-Khaiary, "Least-squares regression of adsorption of adsorption equilibrium data: Comparing the options", J. Hazard. Mater. vol. 158 , pp. 73-87, 2008

[22] M.C. Ncibi, "Applicability of some statistical tools to predict optimum adsorption isotherm after linear and non-linear regression analysis", J. Hazard. Mater., Vol. 153, pp. 207-212, 2008.

[23] M. Badertscher, and E. Pretsch, "Bad results from good data", Trend. Anal. Chem., vol. 25, pp. 1131-1138, 2006..

[24] G.L. Dotto, E.C. Lima, and L.A.A. Pinto, "Biosorption of food dyes onto Spirulina platensis nanoparticles equilibrium isotherm and thermodynamic analysis", Bioresource Technol., vol. 103, pp.123-130, 2012.

(c) Chiachung Chen; Licensee Bentham Open.

This is an open access article licensed under the terms of the Creative Commons Attribution Non-Commercial License (http://creativecommons.org/licenses/by-nc/3.0/) which permits unrestricted, non-commercial use, distribution and reproduction in any medium, provided the work is properly cited. 